\title{
Single-Channel Analysis of Four Distinct Classes of Potassium Channels in Drosophila Muscle
}

\author{
William N. Zagotta, Michael S. Brainard, and Richard W. Aldrich \\ Department of Neurobiology, Stanford University School of Medicine, Stanford, California 94305
}

\begin{abstract}
A number of mutations have been shown to affect potassium channels in Drosophila muscle. Single-channel analysis of the effects of mutations will prove a powerful approach for studying the molecular mechanisms of ion channel gating. As an initial step towards studying the effects of mutations at the single-channel level, we have characterized wild-type potassium channels in cultured embryonic myotubes using whole-cell, cell-attached, inside-out, and outside-out configurations of the patch-clamp technique.
\end{abstract}

The myotubes differentiate in vitro from primary cultures of late-gastrula stage embryos of Drosophila. The whole-cell outward currents develop in a characteristic sequence. At $8 \mathrm{hr}$ after plating a small delayed outward current is present. Between 10 and $12 \mathrm{hr}$ after plating an A-type outward current develops, followed, between 13 and $16 \mathrm{hr}$, by a large increase in the delayed current. The A-type current is absent at all developmental stages in myotubes homozygous for the mutant $S{ }^{\kappa s i 3 s}$.

At least 4 different types of potassium channels contribute to the whole-cell outward currents: a fast transient 14 pS A-type potassium channel $\left(A_{1}\right)$, a slowly inactivating 14 pS potassium channel $\left(K_{D}\right)$, a $40 \mathrm{pS}$ potassium channel that does not inactivate during voltage pulses up to $2.4 \mathrm{sec}$ in duration $\left(K_{o}\right)$, and a $90 \mathrm{pS}$ potassium channel that is strongly activated by membrane stretch ( $K_{\mathrm{sT}}$ ). Channels indistinguishable from the $K_{D}$ and $K_{s t}$ channels were also observed in patch-clamp studies on larval body wall muscle fibers. $A_{1}$ channels were also present in intact dorsal longitudinal flight muscles.

The $A_{1}$ channel underlies the rapidly inactivating component of the whole-cell current. It inactivates with a similar time course and voltage dependence to the A-current and is similarly blocked by $5 \mathrm{~mm}$ 4-aminopyridine. The $K_{D}$ channel underlies a large fraction of the delayed component of the whole-cell current. Ensemble averages of single $K_{D}$ channels inactivate with the same time course as the delayed current. The $K_{0}$ channel represents a smaller fraction of the wholecell delayed outward current. Its increase in open probability with voltage is due primarily to a voltage dependence of its closed times. The $K_{5 T}$ channel is voltage and calcium independent and would therefore only contribute to the leak whole-cell current.

\footnotetext{
Received Mar. 3, 1988; accepted May 13, 1988.

We thank Dr. Susan Germeraad for many helpful discussions. This work was supported by NS 23294, Training Grants MH 17047 and NS 07158, and Alfred P. Sloan Research Fellowship to R.W.A., and an NSF Graduate Fellowship to M.S.B.

Correspondence should be addressed to Richard W. Aldrich at the above address.

Copyright (C) 1988 Society for Neuroscience $0270-6474 / 88 / 124765-15 \$ 02.00 / 0$
}

Macroscopic voltage-clamp studies have revealed that many cell membranes possess a variety of potassium channels with distinct kinetics, pharmacology, and gating mechanisms (Thompson and Aldrich, 1980; Latorre et al., 1984; Rudy, 1988). These have been classified into a number of categories, including A-type, delayed rectifier, inward rectifier, and $\mathrm{Ca}^{2+}$-activated potassium channels. Single-channel recording studies have further refined these classifications by showing that some of the kinetically distinct macroscopic currents represent contributions from 2 or more distinct channel types (Marty and Neher, 1985; Hoshi and Aldrich, 1988). Furthermorc, the versatility of the patch-clamp technique has allowed the description of many additional classes of potassium channel activated by such things as membrane stretch (Brezden et al., 1986; Sigurdson et al., 1987), intracellular nucleotides (Noma, 1983; Kakei et al., 1985; Spruce et al., 1985; Ohno-Shosaku et al., 1987; Ribalet and Ciani, 1987) and GTP-binding proteins (Breitwieser and Szabo, 1985; Pfaffinger et al., 1985; Logothetis et al., 1987; Yatani et al., 1987). This diversity in channel types raises interesting questions regarding the structural relationships between the different potassium channels, which can best be answered through a combination of biophysical and molecular techniques.

The ability to combine single-channel recording and analysis with genetic and molecular manipulations makes Drosophila an ideal organism for studies of the structural and functional relationships between the various types of potassium channels and the molecular gating mechanisms of individual classes of channels. A number of behavioral mutations have been isolated and shown to affect muscle and neuronal excitability (Ganetzky and Wu, 1986; Salkoff and Tanouye, 1986; Tanouye et al., 1986; Papazian et al., 1988). In Drosophila, once a mutation affecting an ion channel has been isolated, the gene can be cloned by the techniques of chromosomal walking or transposon tagging. This approach can enable a molecular analysis of genes whose products, like potassium channels, are in low abundance. The usefulness of this approach has recently been illustrated by the successful cloning of the Shaker gene, which codes for a structural component of an A-type potassium channel (Baumann et al., 1987; Kamb et al., 1987; Papazian et al., 1987; Tempel et al., 1987; Schwarz et al., 1988; Timpe et al., 1988). Once a channel gene has been cloned, its structure can be altered with site-directed mutagenesis, and it can be reintroduced into the fly with germline transformation. Channels from transformed flies can be studied with single-channel recording, thereby allowing functional analysis of altered channel proteins in their normal environment.

Previous work has demonstrated that muscle is a good tissue in which to study mutant effects on Drosophila potassium chan- 
nels. Three different muscle preparations have been employed to examine the potassium currents under voltage-clamp conditions: pupal dorsal longitudinal flight muscles (DLM) (Salkoff and Wyman, 1981a, b; Salkoff, 1983, a, b; Elkins et al., 1986; Wei and Salkoff, 1986; Timpe and Jan, 1987), larval body wall muscles (Wu et al., 1983; Wu and Haugland, 1985), and cultured embryonic myotubes (Solc et al., 1987). All 3 muscle types contain a fast transient potassium current, the A-current, which is eliminated by many mutations of the Shaker locus and altered by others. In addition, each contains a delayed potassium current. The pupal DLMs and larval body wall muscles have also been shown to express a transient calcium-activated potassium current that is eliminated by mutations of the slowpoke locus. Previous work on Drosophila muscle potassium channels has predominantly used macroscopic voltagc-clamp tcchniques. The analysis of single-channel data can provide insight into channel gating mechanisms not possible with standard macroscopic voltage-clamp techniques. With the eventual goal of determining the functional consequences of known channel mutations, we have characterized wild-type potassium channels in cultured embryonic myotubes, using whole-cell and single-channel voltage-clamp techniques. We have also studied single polassium channel currents in undissociated larval and pupal muscle to compare the types of channels found in muscle at different developmental stages.

\section{Materials and Methods}

Drosophila stocks. Drosophila stocks were maintaincd at $26^{\circ} \mathrm{C}$ on a cornmeal-yeast-dextrose-sucrose medium. The wild-type strain was Canton-S, and the mutant strain $S h^{K S / 33}$ was obtained from L. Salkoff.

Cell culture. Cell cultures of Drosophila myotubes were prepared according to the procedure of Seecof (1979). Late-gastrula stage embryos were collected and dechorionated in a $50 \%$ bleach solution for $1 \mathrm{~min}$. The cells were then removed from the embryos with sharp micropipets and dispersed onto untreated glass coverslips. The cells were allowed to differentiate in a modified Schneider's medium containing $20 \%$ heatinactivated fetal calf serum and $8 \mathrm{mU} / \mathrm{ml}$ of insulin at $26^{\circ} \mathrm{C}$. This temperature has been shown to maximize the contractile activity of myotubes in these cultures (Seecof and Donady, 1972).

Cells from late-gastrula stage embryos differentiate in culture into several identifiable cell types, including neurons and myotubes (Seecof et al., 1971). Seecof et al. reported that the mesenchyme-like myoblasts divide in vitro about $5 \mathrm{hr}$ after the initiation of gastrulation or approximately $2 \mathrm{hr}$ after plating. Over the course of the next $7 \mathrm{hr}$, these daughter cells align themselves with other myoblasts and fuse with them to make elongated, multinucleated myotubes (Seecof et al., 1973). Many of the myotubes twitch spontaneously in the culture dish or in physiological saline solutions containing $2 \mathrm{mM} \mathrm{Ca}{ }^{2+}$, and nearly all of them exhibit a pronounced, prolonged contracture when exposed to a solution containing high $\mathrm{K}^{+}(140 \mathrm{~mm})$ and $\mathrm{Ca}^{2+}(2 \mathrm{~mm})$.

Larval and pupal muscle preparations. Larval body wall muscles were prepared by a modification of the procedure of Jan and Jan (1976). Third instar larvae were etherized, and glued, ventral side down, to a glass coverslip with cyanoacrylate glue (Krazy Glue inc.). The cuticle was slit with a razorblade along the dorsal midline from the anterior to the posterior pole, and the viscera were removed. The lateral and dorsal cuticle were trimmed away, leaving only the ventral cuticle with its associated body wall musculature intact. The preparation was then digested for 30 min-2 hr in a solution containing high $\mathrm{K}^{+}$and no added calcium with $400 \mathrm{U} / \mathrm{ml}$ of collagenase (Sigma, Type I) and transferred to a chamber for physiology.

DLMs were prepared from pupae between 70 and $80 \mathrm{hr}$ after pupariation. The pupal cases were glued by their lateral side to a glass coverslip with cyanoacrylate glue. Pupae were then sectioned midsagitally with a razorblade, exposing the medial portion of 4-6 of the 12 DLMs in the thorax. The preparation was then treated with collagenase as described above and transferred to the recording chamber.

Electrophysiology. Electrophysiological recordings were done 8-24 hr after plating of the cells. The cell membranes were voltage-clamped, and current was recorded with a List EPC-7 patch-clamp amplifier (List Medical/Medical Systems, Greenvale, NY). The output of the patch clamp was low-pass-filtered through an 8-pole Bessel filter, digitized at frequencies indicated in the figure legends, and stored on the computer for later analysis. A Digital Equipment Corporation LSI 11/73-based minicomputer system (Indec Systems, Sunnyvale, CA) controlled the voltage-clamp protocols and was used for data analysis.

The pipet junction potential was nulled just prior to seal formation for both whole-cell and single-channel recording. The voltage error due to junction potential is estimated to be less than $5 \mathrm{mV}$ based on the reversal potential of potassium channels recorded in experiments done in solutions with symmetrical $\mathrm{K}^{+}$concentrations.

For whole-cell recordings, electrodes with input resistances of 1-2 $\mathrm{M} \Omega$ in standard solutions were used to maintain a low series resistance. The input resistance of the cells was usually greater than $2 \mathrm{G} \Omega$. Typically, for currents greater than $200 \mathrm{pA}, 50-80 \%$ of the series resistance was electronically compensated. For currents less than $1 \mathrm{nA}$, the largest outward current considered in these experiments, this compensation results in a maximum series resistance error of $2 \mathrm{mV}$, assuming a series resistance of $4 \mathrm{M} \Omega, 2-4$ times the pipet resistance. Most of the capacitative current was subtracted elcctronically using the capacitance compensation circuitry of the patch clamp. The remaining uncompensated capacitative current and ohmic leak current were digitally subtracted from the data using leak templates scaled up to the appropriate voltages. The leak templates were constructed by fitting smooth functions to the average current response to $20 \mathrm{mV}$ depolarizing steps from a holding voltage of $-70 \mathrm{mV}$. No time-dependent currents were activated in this voltage range.

Single-channel currents were recorded using the cell-attached, insideout, and outside-out configurations of the patch-clamp technique (Hamill et al., 1981). In voltage-step experiments, the linear leak and uncompensated capacitative currents were digitally subtracted using leak templates made from sweeps with no openings. For the ensemble averages and duration histograms, the single-channel data were idealized using a 50\% amplitude criterion to detect opening and closing transitions. The ensemble averages that have been expressed as probability units in the figures were determined by dividing the current averages by the number of channels in the patch (typically only 1) and the unitary current amplitude. In voltage-ramp experiments, the leak current was subtracted using leak templates constructed from records or segments of records with no openings. For experiments involving stretch-activated channels, pressure applied to the patch pipet was monitored with a water manometer.

Solutions. For whole-cell and outside-out experiments the compositions of the solutions were as follows (in mM): external (bath) $140 \mathrm{NaCl}$,

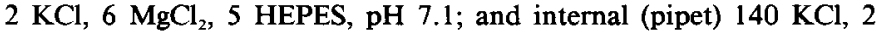
$\mathrm{MgCl}_{2}, 11$ EGTA, 10 HEPES, pH 7.1. For cell-attached and inside-out experiments on the cultured myotubes and larval muscle the external solution was used in the pipet and the internal, high- $\mathrm{K}^{+}$solution was used in the bath. In this high- $\mathrm{K}^{+}$solution the cell resting potential should be close to $0 \mathrm{mV}$, and the voltages reported are therefore close to the actual voltage across the membrane. No differences were seen in the voltage dependence for any of the channels between cell-attached and cell-free patches. The free $\mathrm{Ca}^{2+}$ concentration of the internal solution was estimated to be approximately $1 \mathrm{nM}$. For the cell-attached experiments on pupal DLMs, gluconate was substituted for $\mathrm{Cl}^{-}$in both the external and internal solutions to eliminate the current through $\mathrm{Cl}^{-}$ channels.

The temperature of the recording chamber was controlled at $22 \pm$ $0.2^{\circ} \mathrm{C}$ by a Peltier thermoelectric device. The results presented are representative of over 400 whole-cell and single-channel experiments.

\section{Results}

\section{Whole-cell potassium currents}

Whole-cell outward currents recorded from cultured embryonic myotubes exhibit both a rapidly inactivating and a delayed, sustained component. These currents develop in a characteristic sequence after plating of cells. At the earliest times we have recorded from myotubes, $8 \mathrm{hr}$ after plating, there is a small outward current which does not inactivate during a $60-\mathrm{msec}-$ long voltage step (Fig. 1 $A$ ). Over the next couple of hours, the current amplitude does not increase significantly. At about 10 $\mathrm{hr}$ there is an abrupt appearance of a comparatively large, rap- 
8-9 hrs

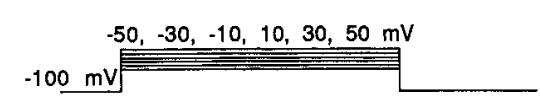

A

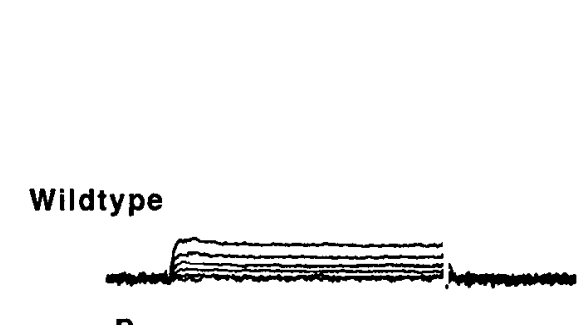

D

$s h^{K S 133}$

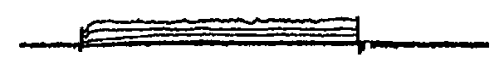

$200 \mathrm{pA}$

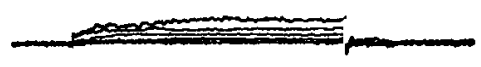

10-12 hrs

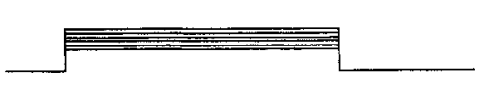

B

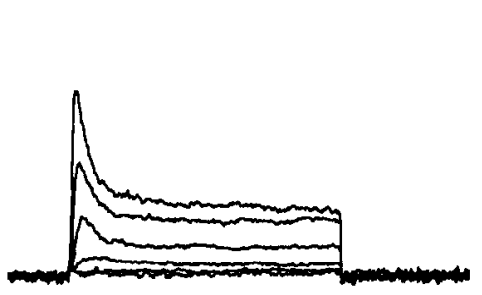

E

$200 \mathrm{pA}$
$10 \mathrm{~ms}$
13-16 hrs

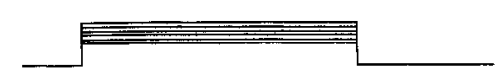

C

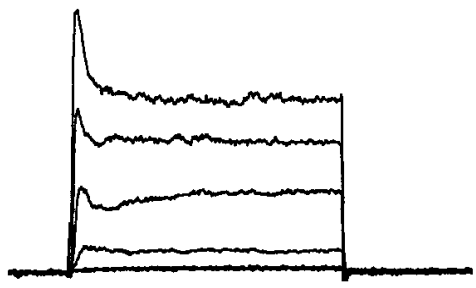

F

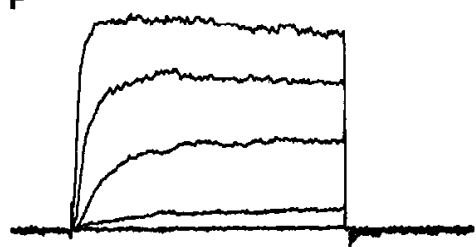

$200 \mathrm{pA}$

$10 \mathrm{~ms}$

Figure 1. Whole-cell currents in cultured embryonic myotubes from wild-type $(A-C)$ and $S h^{K S I 33}$ mutant $(D-F)$ Drosophila at 3 times after dissociation and plating. The myotube currents were recorded from 8-9 hr $(A, D), 10-12 \mathrm{hr}(B, E)$, and 13-16 hr $(C, F)$ after plating. All currents shown were recorded from myotubes cultured on the same day under identical conditions. The membrane potential was stepped from a holding potential of $-70 \mathrm{mV}$ to a prepulse potential of $-100 \mathrm{mV}$ for $500 \mathrm{msec}$ and then depolarized for 60 msec to command potentials between -50 and $50 \mathrm{mV}$ in $20 \mathrm{mV}$ increments. This voltage pulse protocol is shown at the top. Voltage steps were applied every 5 sec.

idly inactivating current component. There is a time window from roughly 10 to $12 \mathrm{hr}$ during which the rapidly inactivating current is the predominant component of the whole-cell current (Fig. $1 B$ ). After this, the rapidly inactivating current does not increase much further, but there is a substantial increase in the delayed current (Fig. $1 C$ ). Because of the overlap in the time course of the transient and delayed currents, an apparent increase in the peak transient current is seen. Although this developmental trend is clear, the absolute magnitudes of peak and delayed currents vary between cells at any given developmental time, even when currents are normalized by cell capacitance. This sequence of outward current development is similar to what has been observed in voltage-clamped pupal muscle after pupariation (Salkoff and Wyman, 1981a). Assuming the sequence of appearance of the outward current components in vitro is similar to what would have occurred in the embryos, this result shows that the sequential appcarance of current components is the same during embryonic and adult development.

The independent developmental time courses of the rapidly inactivating and delayed whole-cell current components suggest that distinct populations of ion channels may underlie them. Furthermore, in these myotubes, the excitability mutant $S h^{K S 133}$ selectively eliminates the rapidly inactivating whole-cell current (Solc et al., 1987), su that at all developmental times the delayed current can be observed in relative isolation (Fig. 1, D-F). $S h^{K S / 33}$ also eliminates the rapidly inactivating outward current in larval and pupal muscle (Salkoff and Wyman, 1981b; Wu et al., 1983). In agreement with results from larval and pupal muscle, these results support the idea that genetically distinct molecules underlie different components of the whole-cell outward currents.
This is further substantiated by the differential sensitivity of the 2 components to the pharmacological agents 3-aminopyridine or 4-aminopyridine (4-AP). In this preparation (see below), as in other cell types (Thompson, 1977; Salkoff and Wyman, 1981b), external aminopyridines preferentially block the rapidly inactivating component of whole-cell current.

In the remainder of this section we will describe single ion channel currents recorded from these myotubes and show how they contribute to the whole-cell currents.

\section{Single Potassium Channels}

We have recorded single-channel currents from 4 potassium channel types in cultured myotubes, which we refer to as $A_{1}$, $\mathrm{K}_{\mathrm{D}}, \mathrm{K}_{\mathrm{O}}$, and $\mathrm{K}_{\mathrm{ST}}$. Representative current traces and open channel current-voltage relations for the 4 classes are compared in Figure 2 . The $A_{1}$ channel has a conductance of $13-16 \mathrm{pS}$ and underlies the rapidly inactivating component of the whole-cell current. The $\mathrm{K}_{\mathrm{D}}$ channel has a similar conductance, 11-16 pS, but inactivates much more slowly and underlies most of the delayed whole-cell current. The third voltage-sensitive channel, $\mathrm{K}_{\mathrm{O}}$, has a conductance of $40-45 \mathrm{pS}$. It is noninactivating but represents only a small fraction of delayed current. The $\mathrm{K}_{\mathrm{ST}}$ channel, with a slope conductance of $90 \mathrm{pS}$ at $30 \mathrm{mV}$, is activated by stretch of the membrane but is relatively voltage independent. All of the channel currents in this figure were recorded in cell-free membrane patches with external solution bathing the normal extracellular face of the membrane and internal solution bathing the cytoplasmic face. In these solutions the only ion with a negative equilibrium potential is potassium. Because all of these channel types have extrapolated reversal potentials more neg- 

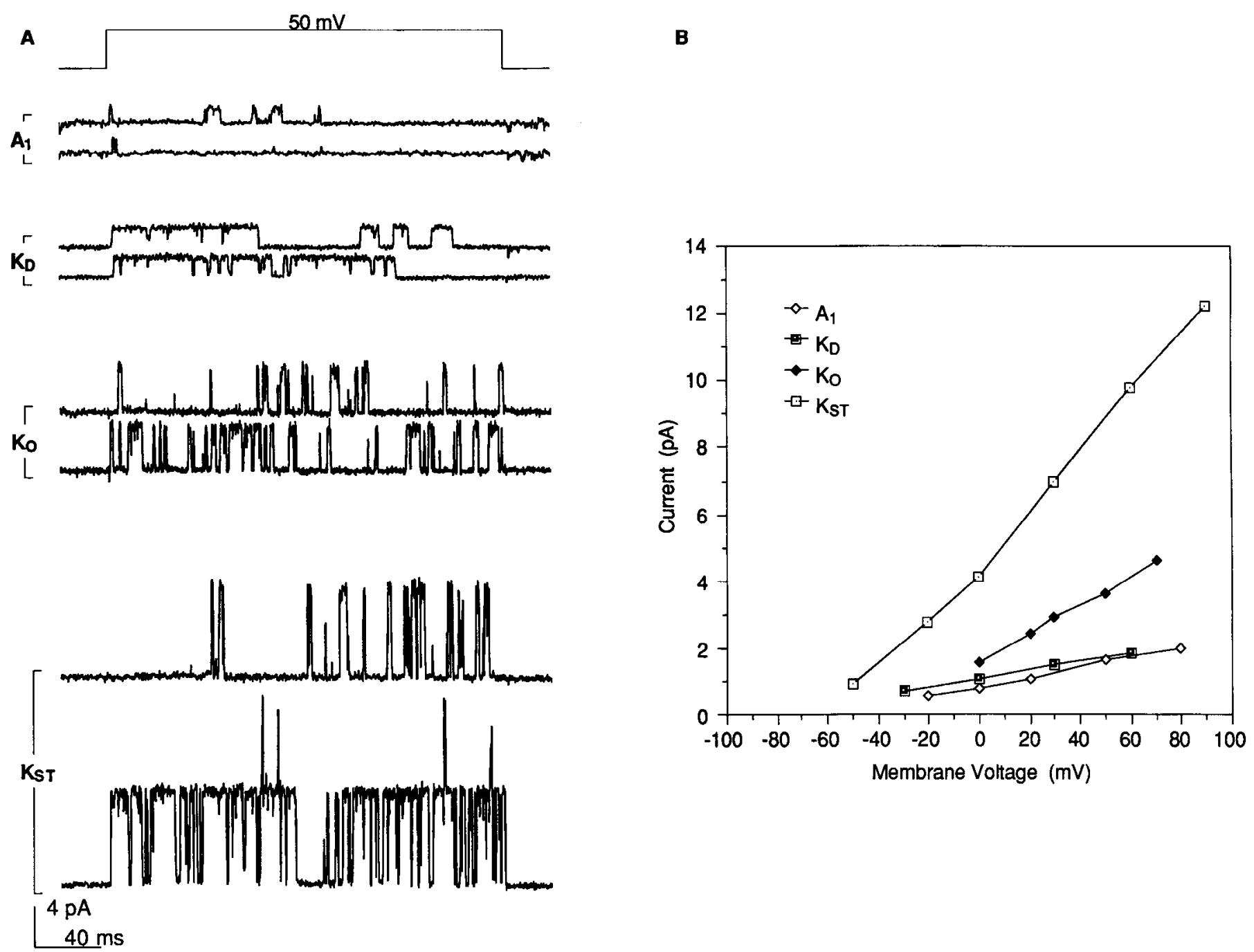

Figure 2. Summary of single potassium channel types in the cultured embryonic myotubes. $A$, Representative current traces from the 4 single potassium channel types: $A_{1}, K_{D}, K_{o}$, and $K_{s T}$. The currents were recorded in outside-out patches with voltage steps from -100 to $50 \mathrm{mV}$. The voltage pulse protocol is shown at the top. The data were filtered at $2000 \mathrm{~Hz}$ and digitized at $100 \mu \mathrm{sec}$ per point. $B$, Single-channel current-voltage relations for the 4 potassium channel types in cell-free patches. Although the current-voltage relationships are not strictly linear, the conductances of the 4 channel types, determined from straight lines fit to the curves at $30 \mathrm{mV}$ wcre as follows: $\mathrm{A}_{1}, 15 \mathrm{pS} ; \mathrm{K}_{\mathrm{D}}, 13 \mathrm{pS} ; \mathrm{K}_{\mathrm{O}}, 43 \mathrm{pS} ; \mathrm{K}_{\mathrm{sT}}, 90 \mathrm{pS}$.

ative than $-40 \mathrm{mV}$, they are all primarily $\mathrm{K}^{+}$selective. Because the internal solution has $\mathrm{Ca}^{2+}$ buffered to about $1 \mathrm{nM}$, none of these channels strictly require $\mathrm{Ca}^{2+}$ for their gating.

\section{A, channels}

An example of the single potassium channels that underlie the A-current is shown in Figure $3 A$. These have been designated $A_{1}$ channels to differentiate them from the $A_{2}$ channel found in Drosophila larval neurons (Solc et al., 1987; Solc and Aldrich, 1988). The $A_{1}$ channels open rapidly after a voltage step in single openings or occasionally in short bursts of 2 or 3 openings. Occasionally, the channel will reopen later in the pulse after a relatively long closure. The time courses of the open probability determined from the averages of many such single-channel traces are shown in Figure 3. The macroscopic inactivation rate of the ensemble average of records elicited by steps to $50 \mathrm{mV}$ (Fig. $3 B$ ) is considerably more rapid than that from steps to $0 \mathrm{mV}$ (Fig. $3 A$ ). Examination of the single-channel behavior at different voltages reveals how the voltage dependence of the ensemble averages arises. The times from the initiation of the voltage pulse to the first opening (first latencies) are strongly voltage dependent, but the durations of the openings do not change significantly with voltage. Thus, the macroscopic inactivation rate of the ensemble averages has a time course determined by the first latencies at low voltages. As the voltage increases, the first latencies become shorter, producing more rapid macroscopic inactivation. This type of gating scheme, with the voltage dependence residing in opening transitions but not in inactivating ones is qualitatively similar to sodium channel gating (Armstrong and Bezanilla, 1977; Aldrich et al., 1983; Aldrich and Stevens, 1987). The single $A_{1}$ channel currents in this figure were recorded in the cell-attached configuration; in excised patches $A_{1}$ channels have more variability in the inactivation rate of their ensemble averages ( $c f$. Fig. 4) and often have a greater number of openings per voltage step ( $c f$. Solc et al., Fig. $2 A)$. Furthermore, $A_{1}$ channel currents recorded in cell-attached patches had consistently higher conductances (around $20 \mathrm{pS}$ ) than shown for $A_{1}$ channels in cell-free patches (Fig. 2).

Both the absolute time course of the ensemble averages and their voltage dependence closely mimic those of the whole-cell A-currents recorded in these myotubes between 10 and $13 \mathrm{hr}$ where the A-current is most isolated from contamination by 
A
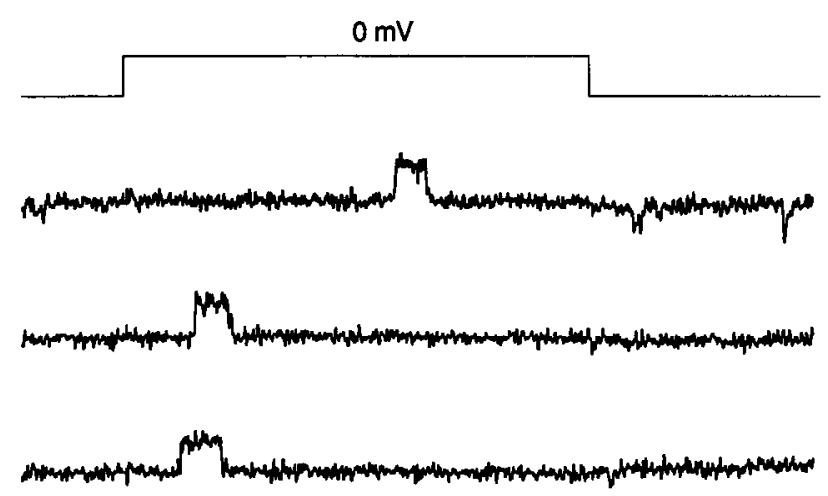

B
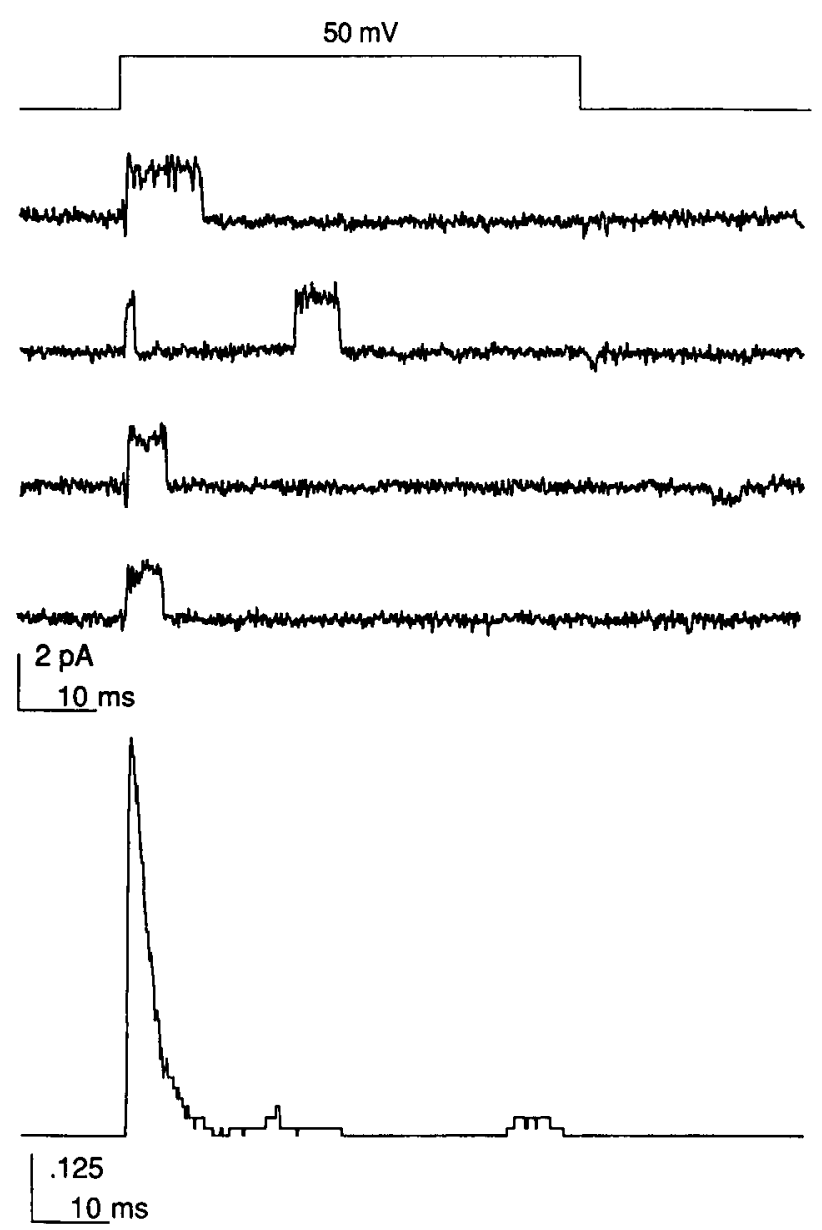

Figure 3. Single $\mathrm{A}_{1}$ channel currents recorded in a cell-attached patch with voltage steps to $0 \mathrm{mV}(A)$ and $50 \mathrm{mV}(B)$ after a $500 \mathrm{msec}$ prepulse to $-100 \mathrm{mV}$. Each panel shows 4 representative current traces from a patch containing a single $A_{1}$ channel, followed by an ensemble average of 70 such traces at the same potential. The ensemble averages are expressed as probabilities. The voltage pulse protocols are shown at the top. The data were filtered at $2000 \mathrm{~Hz}$ and digitized at $50 \mu \mathrm{sec}$ per point.

other types of potassium currents (Fig. 1B). This similarity strongly suggests that these single channels underlie the rapidly inactivating component of the whole-cell current. The voltage dependence of prepulse inactivation of single $A_{1}$ channels is also similar to that of the whole-cell A-current (Solc et al., 1987).

In addition to having similar time courses and voltage dependencies, the $A_{1}$ channels and whole-cell $A$-current are both blocked by 4-AP. In a cell expressing both A-current and delayed current, the A-current is preferentially blocked by 4-AP (Fig. $4 A$ ). Note that the time course of the 4-AP-sensitive current is similar to both the $A_{1}$ channel ensemble averages (Fig. $3 B$ ) and the whole-cell currents at $10-12 \mathrm{hr}$ after plating (Fig. $1 B$ ). As shown in Figure $4 B$, the single $A_{1}$ channels are also blocked by 4-AP. These ensemble averages were recorded from a single $A_{t}$ channel in the outside-out configuration. When $5 \mathrm{mM} 4-\mathrm{AP}$ was added to the external solution, the frequency of channel opening was greatly diminished, though occasional openings still occurred. This manifests itself as a dramatic decrease in the amplitude of the ensemble average, as shown in Figure 3B. Upon washing the 4-AP out of the external solution, the frequency of opening partially recovered. The single-channel current amplitude was not affected by 4-AP.

Most of the $A_{1}$ single-channel currents were recorded between 12 and $14 \mathrm{hr}$ after plating; at this time the A-current amplitude is maximal and the single-channel recordings are relatively uncontaminated by other channel types. The frequency of cellattached patches with $A_{1}$ channels was also maximal at this developmental time, reaching a value of approximately $13 \%$ of patches (23 out of 174) in which single-channel events could have been detected. Generally the $A_{1}$ channels occurred in single-channel patches. Frequently the channels would stop opening within a few minutes after seal formation in cell-attached recordings, but occasionally a channcl would last for a much longer period of time.

\section{$K_{D}$ channel}

A second type of voltage-sensitive potassium channel contributes to the delayed whole-cell current. We have called this channel $K_{D}$ because of its similarity to a previously reported potassium channel type in Drosophila larval neurons (Solc and Aldrich, 1988). Current passing through an open $K_{D}$ channel increases linearly with voltage over the range -40 to $+100 \mathrm{mV}$. The channel's slope conductance typically falls between 14 and 16 $\mathrm{pS}$ in cell-attached patches (Fig. $2 B$ ), with a tendency for lower conductances in inside-out patches. Figure 5 shows single-channel records of a $K_{D}$ channel on the same time scale as Figures 1 and 3. Unlike the $A_{1}$ channel, the $K_{D}$ channel typically does not inactivate during a $60 \mathrm{msec}$ voltage step; after opening, the 
A

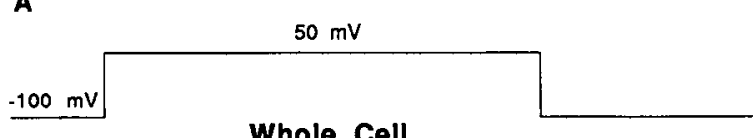

Whole Cell
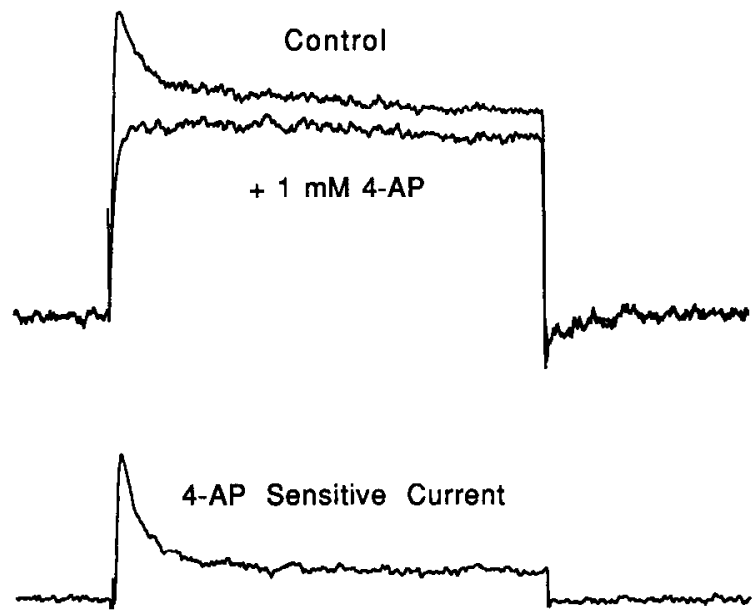

B

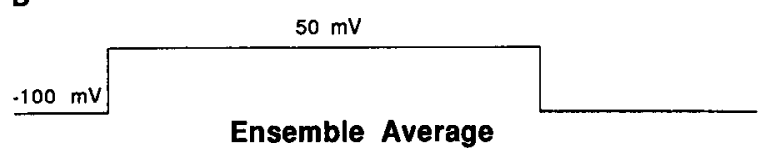

Ensemble Average

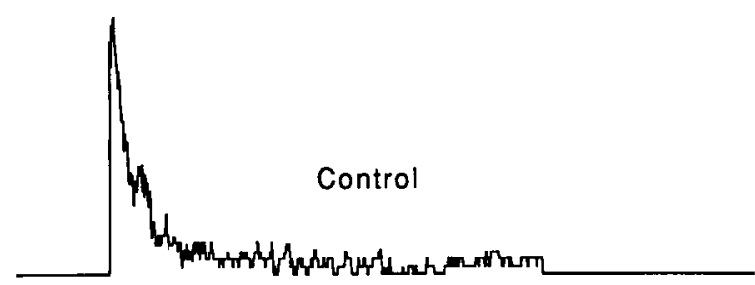

$+5 \mathrm{mM} 4-\mathrm{AP}$

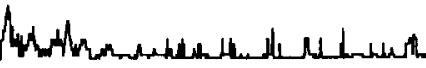

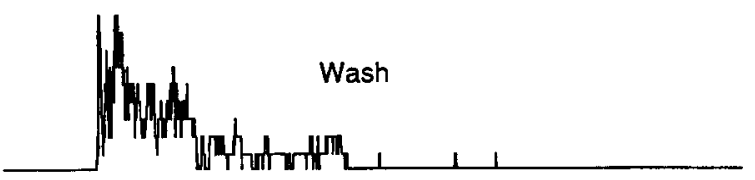

.25

$40 \mathrm{~ms}$

Figure 4. Block by 4-AP of the whole-cell A-current and single $\mathrm{A}_{1}$ channels. A, 4-AP block of the whole-cell A-current. Top panel, Superimposed, the current elicited by voltage steps to $50 \mathrm{mV}$, before and after the addition of $1 \mathrm{~mm}$ 4-AP to the bath solution; bottom panel, time course of the 4-AP-sensitive current, obtained by subtracting the current after the addition of 4-AP from that before its addition. $B, 4-\mathrm{AP}$ block of a single $\mathrm{A}_{1}$ channel in an outside-out patch. Top panel, ensemble average from a single $A_{1}$ channel with voltage steps to $50 \mathrm{mV}$ before the addition of 4 -AP; middle panel, ensemble average from the same channel after 4-AP addition; bottom panel, partial recovery of channel shortly after reintroducing control solutions. The ensemble averages are expressed as probabilities. The voltage protocols are shown at the top.

A
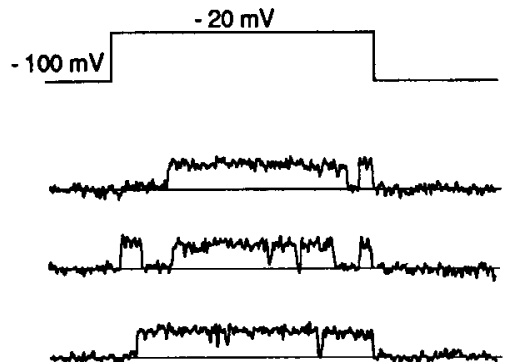

$2 \mathrm{pA}$

$10 \mathrm{~ms}$

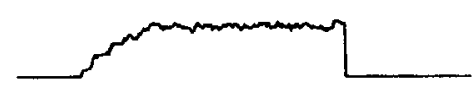

B
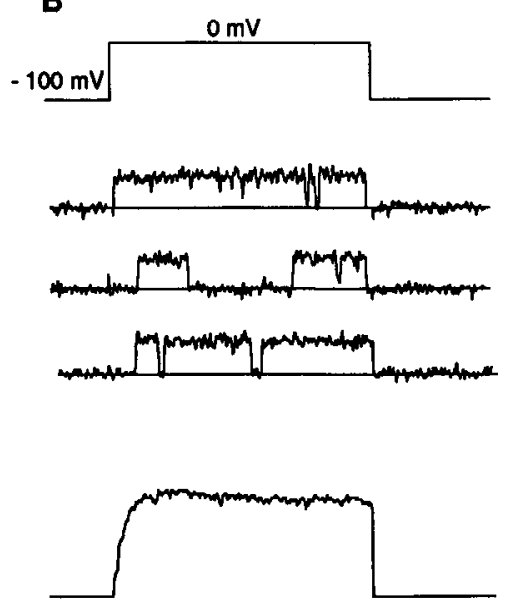
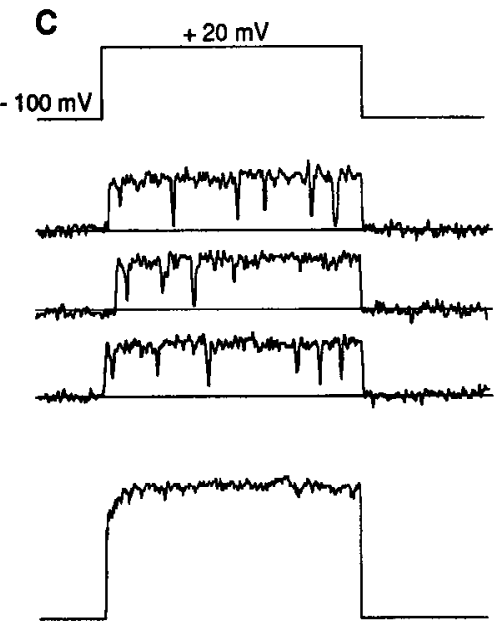

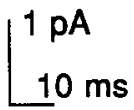

Figure 5. Single $\mathrm{K}_{\mathrm{D}}$ channel currents recorded in a cell-attached patch with voltage steps to $-20 \mathrm{mV}(A), 0 \mathrm{mV}(B)$, and $20 \mathrm{mV}(C)$. Each panel shows 3 representative current traces followed by an ensemble average of 60 such traces at the same potential. The ensemble averages are expressed in units of current. The voltage protocols are shown at the top. The data were filtered at $2000 \mathrm{~Hz}$ and digitized at $100 \mu \mathrm{sec}$ per point. 
A

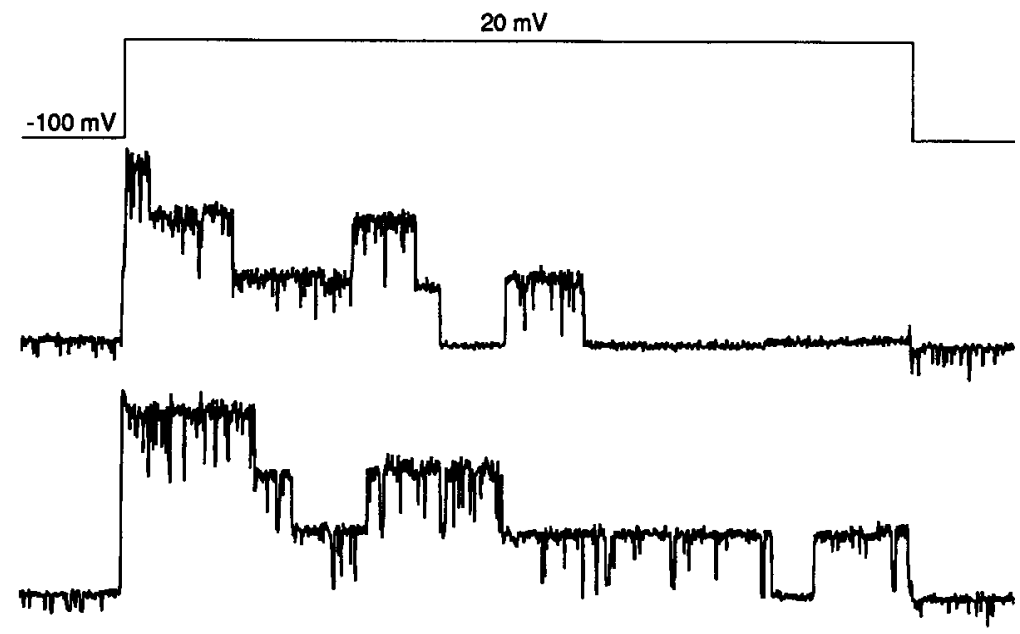

B

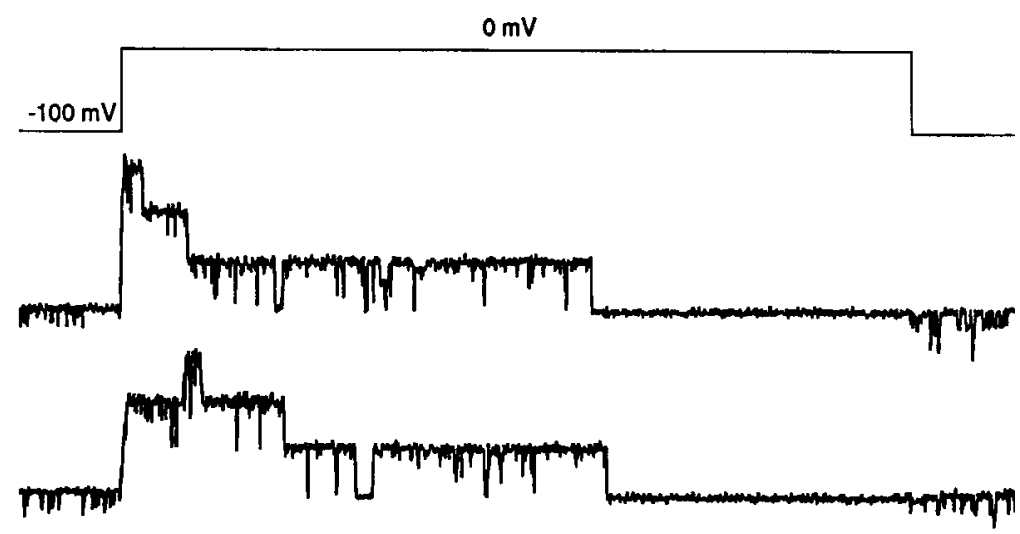

C
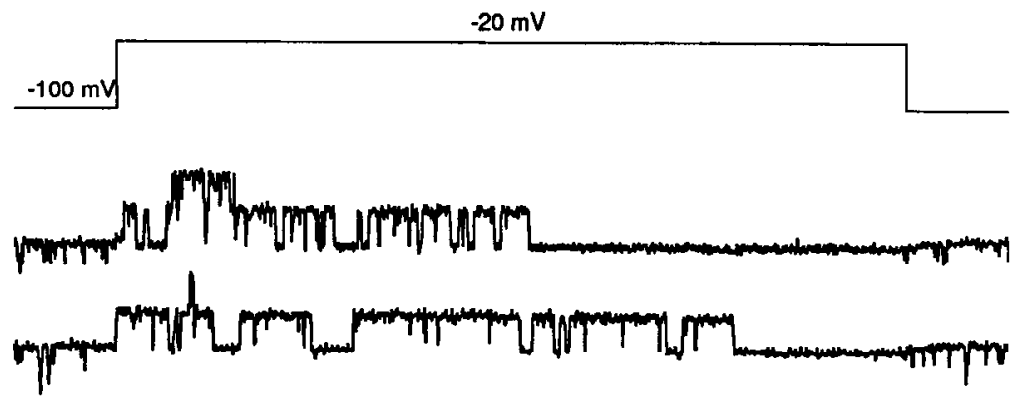<smiles>[R]OC(=O)OCC</smiles>

channel maintains a high open probability and undergoes only transient closings. The median latency to the first channel opening decreases with increasing voltage steps.

These single-channel properties are reflected in the ensemble averages of $K_{D}$ channel activity (Fig. 5 , lower traces). The rate of rise and amplitude of the current contributed by the $K_{D}$ channel both increase with larger depolarizations, and at all voltages the current does not inactivate during a $60 \mathrm{msec}-\mathrm{long}$ depolarization. These features are similar to the delayed wholecell currents of Figure 1 and suggest that the $K_{D}$ channel underlies much of this current.
Figure 6. Single $\mathrm{K}_{\mathrm{D}}$ channel currents on a slower time scale. Currents were recorded from a cell-attached patch with voltage steps to $-20 \mathrm{mV}(A), 0 \mathrm{mV}(B)$, and $20 \mathrm{mV}(C)$. Each panel shows 2 representative current traces from a patch containing $3 \mathrm{~K}_{\mathbf{D}}$ channels. The voltage protocols are shown above the current traces. The data were filtered at $400 \mathrm{~Hz}$ and digitized at $1 \mathrm{msec}$ per point.
During a longer voltage step, $K_{D}$ channels inactivate significantly. Figure 6 shows records from a patch containing $3 K_{D}$ channels that was stepped repeatedly to the same voltages as in Figure 5 but on a 40 times slower time scale. The channels exhibit bursting kinetics, with periods of high open probability containing short closings (evident in Fig. 5 but not well resolved on this time scale), separated by longer closings. Prominent inactivation is apparent on this time scale: Depolarization drives $K_{D}$ channels into a long-duration closed state so that fewer channels are generally open at the end of a $2.4 \mathrm{sec}$ voltage step than at the beginning. The time course of this inactivation can be 


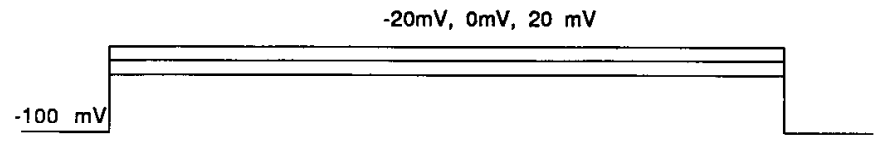

A
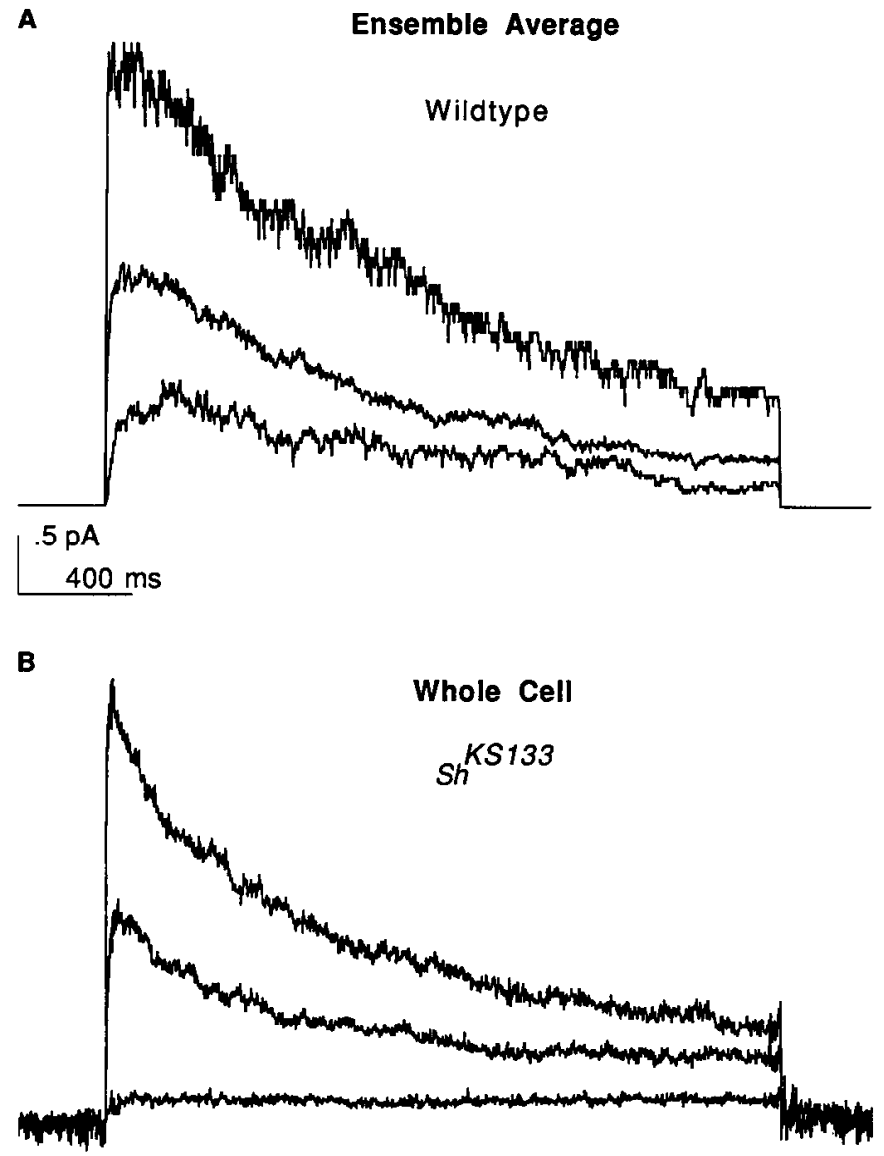

$100 \mathrm{pA}$

$400 \mathrm{~ms}$

Figure 7. Comparison of $\mathrm{K}_{\mathrm{D}}$ ensemble averages with delayed wholecell current. $A$, Superimposed ensemble averages of $\mathrm{K}_{\mathrm{D}}$ channels at -20 , 0 , and $20 \mathrm{mV}$. The ensemble averages are expressed in units of current. Data are from the same patch as that shown in Figure $6 . B$, Delayed whole-cell current at $-20,0$, and $20 \mathrm{mV}$ on the same time scale as in $A$. Currents were recorded in $S h^{K S 133}$ mutant myotubes to eliminate contamination by A-current. The voltage protocol is shown at the top. The data were filtered at $400 \mathrm{~Hz}$ and digitized at $1 \mathrm{msec}$ per point.

seen in ensemble averages made from these single-channel records (Fig. 7A). Whole-cell currents from the mutant $S h^{K S 133}$ (which lacks the rapidly inactivating $\mathrm{A}$-current) are shown at the same voltages for comparison (Fig. $7 B$ ). The similar slow inactivation of the ensemble averages and whole-cell currents again suggests that the $K_{D}$ channels account for most of the delayed current in these myotubes.

$K_{D}$ channels are the most frequently observed voltage-dependent potassium channel in this preparation, and the change in their abundance with time qualitatively parallels the developmental increase in delayed current. Between 11 and $12 \mathrm{hr}$ after plating of cultures, $K_{D}$ channels were observed in $3.7 \%(1 / 27)$ of patches in which single channels could be resolved. Between 13 and $14 \mathrm{hr}$ this had increased to $45 \%(50 / 111)$.

\section{$K_{o}$ Channel}

An example of a third type of voltage-activated potassium channel in Drosophila myotubes, the $\mathrm{K}_{\mathrm{o}}$ channel, is shown in Figure 8. The $K_{\mathrm{o}}$ channel has a linear current-voltage relation over the range of $0-70 \mathrm{mV}$ with a conductance of $40-45 \mathrm{pS}$ (Fig. $2 B$ ). This channel opens in short-duration openings with a frequency that increases with voltage, illustrated in Figure 8 for voltage steps to 0 and $30 \mathrm{mV}$. The ensemble averages of the $K_{o}$ channels, shown in Figure 8, have a rapid activation and little inactivation, even on the same time scale where the $K_{D}$ channel showed a prominent inactivation (Fig. 7). This lack of inactivation, together with the small noninactivating component of the wholecell currents shown in Figure 7 , suggests that the $\mathrm{K}_{\mathrm{o}}$ channel represents only a small fraction of the whole-cell sustained current. This is further supported by the low frequency of occurrence of $K_{O}$ channels in patches relative to $K_{D}$ channels, the low probability of opening of the $\mathrm{K}_{\mathrm{o}}$ channel, and the fact that most of the delayed whole-cell current can be accounted for by the $\mathrm{K}_{\mathrm{D}}$ channels.

Gating of the $\mathrm{K}_{\mathrm{O}}$ channel is voltage dependent. As shown in Figure $9 A$, the probability of the channel being open increases with voltage over the range of -20 to $70 \mathrm{mV}$. This increase in probability is the result of an increased frequency of opening at more positive voltages, and not an increase in the duration of openings. Frequency histograms of open durations are well fitted by single exponentials at all voltages (Fig. 9 $C^{-}$). The mean open duration was relatively voltage independent with a value around $1 \mathrm{msec}$ (Fig. 9B). Frequency histograms for closcd durations (Fig. 9D), however, were not fitted well by single exponentials, but instead required the sum of at least 2 exponentials. In contrast to mean open duration, the mean closed duration was dramatically reduced with increasing voltage (Fig. 9B). Thus, the increase in open probability with voltage is due predominantly to voltage-dependent transitions in the opening pathway.

\section{$K_{S T}$ channel}

We have observed a fourth channel type whose gating is not very sensitive to voltage. We call this channel type $K_{S T}$ because it opens in response to stretch of the cell membrane. Figure 10 shows a recording from a cell-attached patch containing at least $4 \mathrm{~K}_{\mathrm{ST}}$ channels. With voltage held constant at $0 \mathrm{mV}$, and no suction applied to the patch, the channels opened infrequently (Fig. 10A). When a pressure of $-15 \mathrm{~cm} \mathrm{H}_{2} \mathrm{O}$ was applied to the membrane through the patch pipet, the frequency of channel openings increased dramatically, and the probability of finding a $\mathrm{K}_{\mathrm{ST}}$ channel open increased further as more suction was applied (Fig. 10, $B, C$ ). These changes in response to applied suction develop rapidly (within seconds), are maintained for as long as suction is applied to the patch, and are rapidly reversed when suction is removed (Fig. 10D). $\mathrm{K}_{\mathrm{ST}}$ channels continued to respond to suction in cell-free patches, indicating that the cellular machinery required for the transduction of stretch into increased channel openings is tightly associated with the membrane. None of the other channel types described in this article responded similarly to pressure.

Although the patch of Figure 10 was typical in that $\mathrm{K}_{\mathrm{ST}}$ channels were frequently found in clusters of 3 or more, singlechannel patches were also observed, which responded to suction with a monotonic increase in open probability (Fig. 11). Such patches demonstrate that the observed increase in open probability reflects an effect of membrane stretch on the gating of 

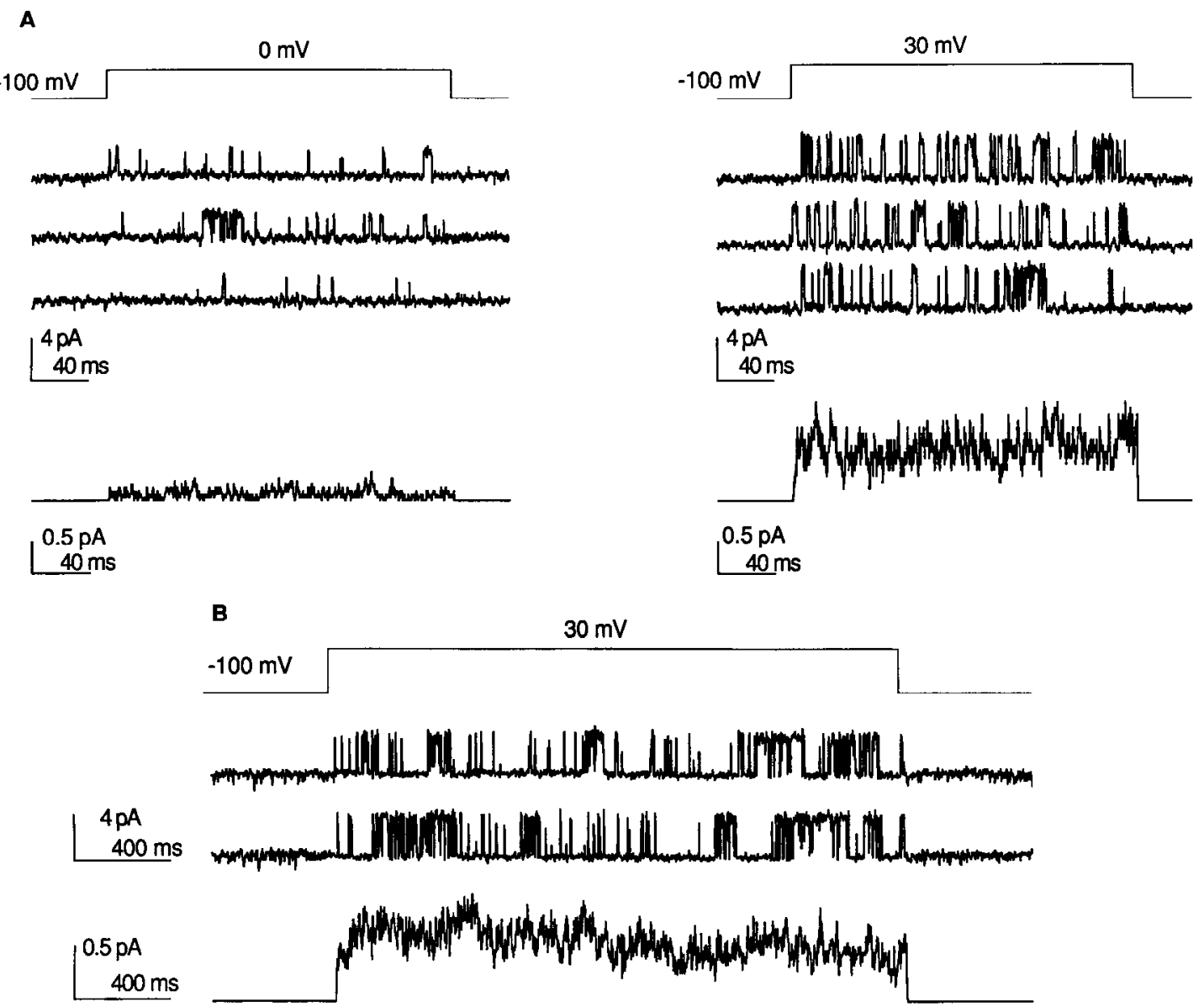

Figure 8. Single $\mathrm{K}_{\mathrm{o}}$ channel currents recorded in cell-attached patches. $A$, Representative current traces from a patch containing $2 \mathrm{~K}_{\mathrm{o}}$ channels that was stepped to $0 \mathrm{mV}$ and $30 \mathrm{mV}$, followed by ensemble averages of 40 such traces at the same potentials. The data were filtered at $2000 \mathrm{~Hz}$ and digitized at $200 \mu \mathrm{sec}$ per point. $B$, Representative current traces and ensemble average from a single $\mathrm{K}_{\mathrm{o}}$ channel on a slower time scale (same as Fig. 7). The ensemble averages were constructed from 80 consecutive current traces elicited by steps to $30 \mathrm{mV}$. The data were filtered at 300 $\mathrm{Hz}$ and digitized at $1 \mathrm{msec}$ per point. The ensemble averages are expressed in units of current. The voltage protocols are shown at the top.

individual $\mathrm{K}_{\mathrm{ST}}$ channels, and not merely the recruitment of more channels into the patch. The open probability of the $\mathrm{K}_{\mathrm{ST}}$ channel in Figure 11 increased from less than 0.05 with no suction to over 0.3 with $-60 \mathrm{~cm} \mathrm{H}_{2} \mathrm{O}$ applied to the patch. This represents a typical sensitivity to suction. Responses were, however, highly variable. This was due in part to variable pipet tip diameter and patch geometry. The larger the (unknown) radius of curvature of membrane in the patch, the greater would be the tension induced by a given amount of suction. Because we cannot reliably estimate tension in the membrane patch, we do not know whether variability in response to applied suction reflects variability in the transduction of stretch to channel openings.

In the absence of applied suction, the open probability of the $\mathrm{K}_{\mathrm{ST}}$ channel is low, usually less than 0.03 , and relatively voltage independent over the range -40 to $+80 \mathrm{mV}$ (Fig. 12). Because the open probability is constant over a wide range of voltages and does not inactivate during maintained depolarizations, it is unlikely that the $K_{\mathrm{ST}}$ channel contributes significantly to the whole-cell currents. The $\mathrm{K}_{\mathrm{ST}}$ channels are rare in patches at times less than $12 \mathrm{hr}$ after plating, but they are the most abundant $\mathrm{K}$ channel type in myotubes older than $16 \mathrm{hr}$.

The $\mathrm{K}_{\mathrm{ST}}$ channel has a nonlinear open channel current-voltage relationship $[i(v)]$ in standard solutions (Fig. 2). Below about 0 $\mathrm{mV}$ the $i(v)$ is superlinear, and above $60 \mathrm{mV}$ it is sublinear. The slope conductance between 0 and $60 \mathrm{mV}$ is about $90 \mathrm{pS}$ and does not vary with applied suction. We have examined the potassium selectivity of the $\mathrm{K}_{\mathrm{ST}}$ channel by determining the reversal potential in various solutions during ramp voltage commands (Fig. 13A). The extrapolated reversal potential for the $\mathrm{K}_{\mathrm{ST}}$ channel is below $-70 \mathrm{mV}$ in standard solutions, and in ionsubstitution experiments in which potassium and sodium equilibrium potentials were independently varied, the measured reversal potential of the $\mathrm{K}_{\mathrm{ST}}$ channel closely matched the theoretical potassium reversal potential (Fig. 13B).

The apparent amplitude of the current passing through a single $\mathrm{K}_{\mathrm{ST}}$ channel is reduced about $50 \%$ by $10 \mathrm{~mm}$ internal or external tetraethylammonium ion (TEA). This is consistent with a blocking and unblocking of the channel by TEA that is too rapid to be resolved with our recording system, similar to the actions of TEA on other potassium channel types (Coronado and Miller, 1979; Yellen, 1984; Shuster and Siegelbaum, 1987).

\section{Single potassium channels in larval and pupal muscle}

To determine if the potassium channels in the cultured embryonic myotubes are also expressed in intact muscle cells, we performed patch-clamp recordings on enzyme-treated muscle fibers from freshly dissected Drosophila. We have exploited 2 different muscle preparations: the body wall muscles of third instar larvae and the DLMs of pupae. For the pupal DLM preparation, pupae were selected $70-80 \mathrm{hr}$ after pupariation. At 
A

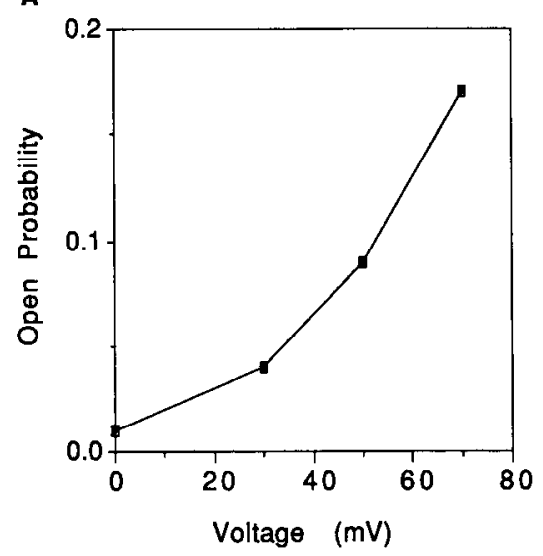

C

Figure 9. Voltage dependence of $\mathbf{K}_{\mathrm{o}}$ channel gating. $A$, Voltage dependence of the open probability. The open probability was determined by the fraction of the time the channel was open during a $240 \mathrm{msec}$ voltage pulse. $B$, Voltage dependence of the mean open time (left) and the mean closed time (right) from the same patch as shown in $A$. $C$, Frequency histogram of open times at 70 $\mathrm{mV}$. The histogram is fitted by a singleexponential function with a time constant of $0.95 \mathrm{msec}$. The bin size is 200 $\mu$ sec. $D$, Frequency histogram of closed times at $70 \mathrm{mV}$. The bin size is $4 \mathrm{msec}$.

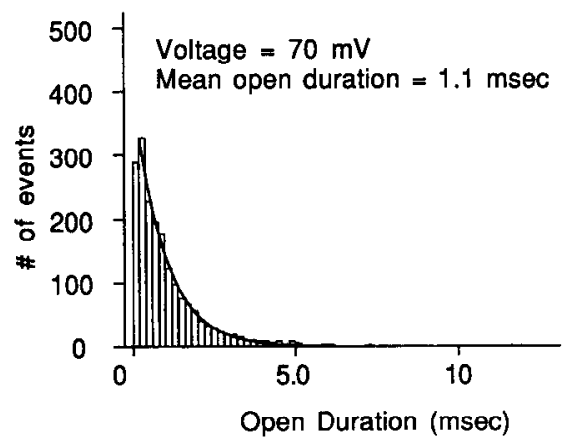

B

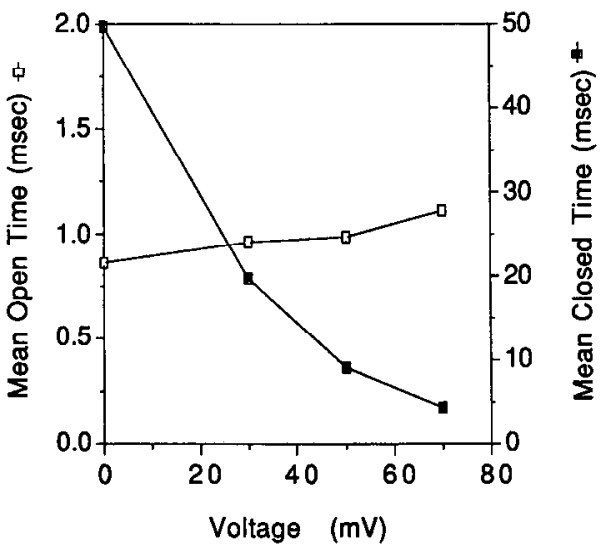

D

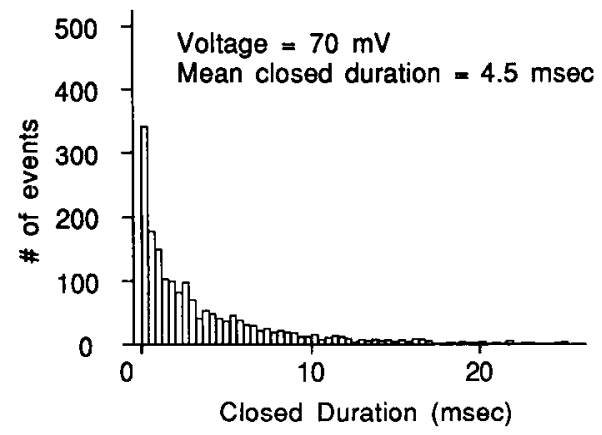

this developmental time, Salkoff and Wyman (1981a) have shown that the DLMs are expressing primarily A-current. As shown in Figure $14 A$, in cell-attached patches on the DLMs we have seen a channel with properties similar to the $A_{1}$ channel of the cultured embryonic myotubes. At $50 \mathrm{mV}$, the unitary current, open times, and ensemble averages of the $A$ channel in the DLMs are indistinguishable from those of the $A_{1}$ channels in myotubes.

In cell-attached patches on the body wall muscles of the larvae, we have observed channels with properties similar to the $\mathrm{K}_{\mathrm{D}}$ channels (Fig. 14B), and $\mathrm{K}_{\mathrm{ST}}$ channels (Fig. 14C). At $0 \mathrm{mV}$ the $K_{D}$ channels of the larval body wall muscles had the unitary current, ensemble average, and burst kinetics characteristic of the $K_{D}$ channels of the cultured myotubes. Similarly, the $K_{S T}$ channels of the larval muscle were indistinguishable from those of the cultured myotubes and exhibited the strong pressure dependence characteristic of that channel. Therefore, between the 2 preparations, 3 of the 4 types of potassium channels described in this paper have been observed.

While the other potassium channels were not detected in the pupal muscle, they would likely be in low abundance at the developmental stage of the pupae that were examined and therefore difficult to detect in patches. In addition, the $A_{1}$ and $K_{0}$ channels have not yet been seen in the larval muscle preparation. The frequency of occurrence of the $K_{o}$ channel in the cultured myotubes is low, and therefore, it might be expected to be more difficult to find and identify unequivocally in the midst of the other channel types. Furthermore, while we have not seen single $A_{1}$ channels in the larval muscle, results from $\mathrm{Wu}$ and colleagues suggest it is present in these cells. Using 2-electrode voltageclamp of these muscle fibers, they have identified a potassium current that has similar voltage dependence, kinetics, and phar- macology to the $A_{1}$ channel and is similarly eliminated by many $S h$ alleles (Wu et al., 1983; Wu and Haugland, 1985).

\section{Discussion}

The macroscopic voltage-activated outward currents of cultured embryonic myotubes are quite similar to those of the pupal DLMs (Salkoff and Wyman, 1981a, b; Salkoff, 1983a, b; Elkins et al., 1986) and larval body wall muscles (Wu et al., 1983; Wu and Haugland, 1985). Each cell type expresses an A channel with similar voltage dependence and pharmacology, which is eliminated or altered by mutations of the Shaker gene. While a quantitative comparison of A-current kinetics is difficult for the 3 preparations because of differences in experimental temperature in previous studies and poor current separation in the larval muscles, each A-current exhibits a rapid activation followed by a voltage-dependent macroscopic inactivation. The A-currents all begin to activate at membrane potentials near $-30 \mathrm{mV}$ and are half-inactivated by short prepulses to potentials between -40 and $-35 \mathrm{mV}$. Aminopyridines block the A-currents in the 3 preparations. The elimination of A-currents in each of the muscle types by many mutations of the $S h$ locus suggests that the channels share, at least in part, a common structure. The delayed outward currents also show a great deal of similarity in the 3 preparations. Each delayed current activates more slowly than the A-current in the same cell and is insensitive to 4-AP and not affected by $S h$ mutations. The delayed current inactivates more slowly than the inactivation of the A-current. The pupal and larval muscle fibers also have been reported to contain a transient calcium current and a transient calcium-dependent outward current (Salkoff and Wyman, 1983; Salkoff, 1983a; Elkins et al., 1986; Singh et al., 1986). A sustained calcium-activated $\mathbf{K}$ current has also been reported in 

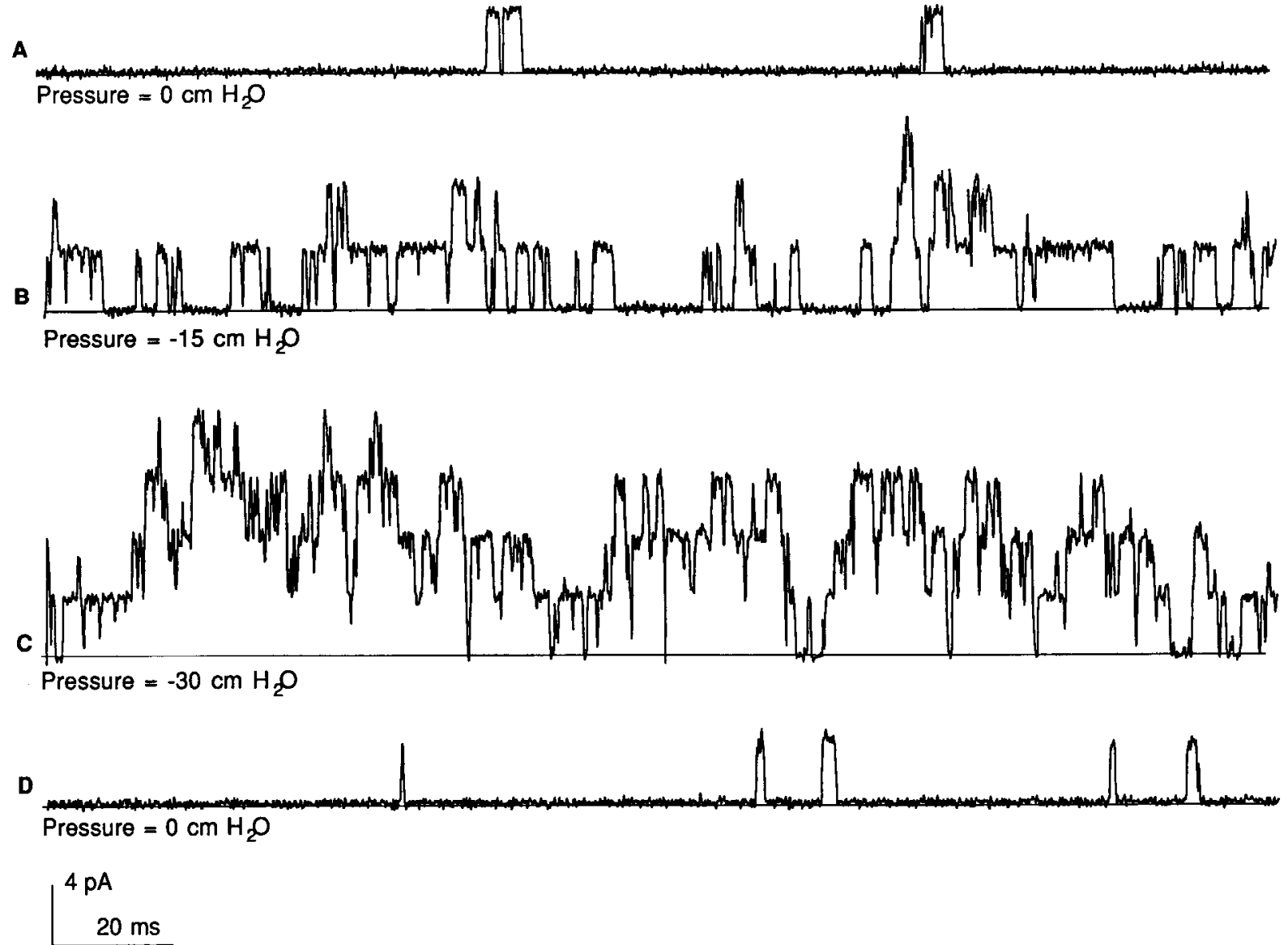

Figure 10. Single $\mathrm{K}_{\mathrm{sT}}$ channel currents recorded in a cell-attached patch with applied pressures of $0 \mathrm{~cm}_{2} \mathrm{O}(A),-15 \mathrm{~cm} \mathrm{H}_{2} \mathrm{O}(B),-30 \mathrm{~cm} \mathrm{H}_{2} \mathrm{O}$ $(C)$, and finally at $0 \mathrm{~cm} \mathrm{H} \mathrm{H}_{2} \mathrm{O}$ again $(D)$ to illustrate that the effect is reversible. Each panel shows a representative segment of a steady-state current record at $0 \mathrm{mV}$. This patch contained at least $4 \mathrm{~K}_{\mathrm{sT}}$ channels. The pressure is expressed as a negative number to indicate that suction was applied to the patch. The data were filtered at $2000 \mathrm{~Hz}$ and digitized at $100 \mu \mathrm{sec}$ per point.

A
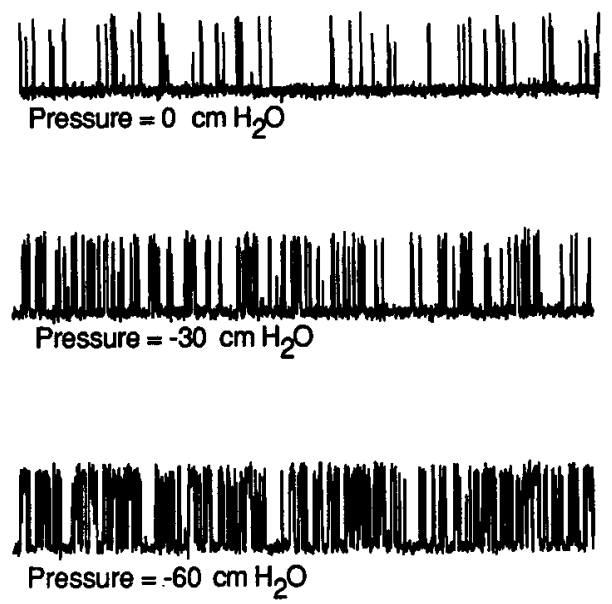

$4 \mathrm{pA}$
$160 \mathrm{~ms}$
B

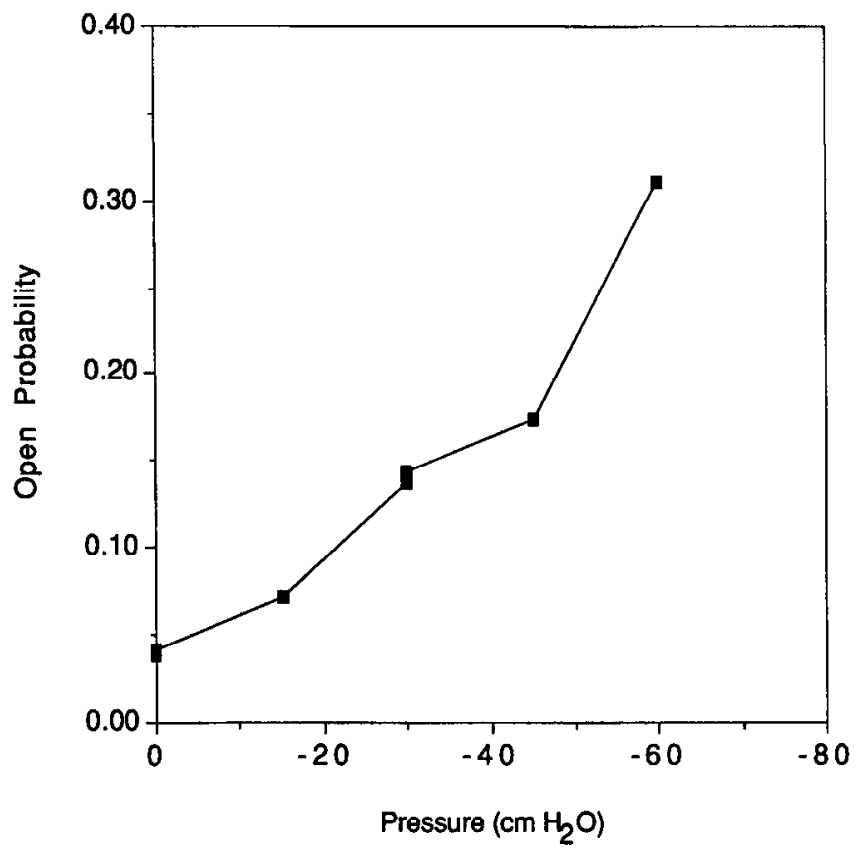

Figure 11. Pressure dependence of a single $\mathrm{K}_{\mathrm{sT}}$ channel. $A$, Representative segments of steady-state records at $0 \mathrm{mV}$ are shown with pressures of $0 \mathrm{~cm} \mathrm{H} \mathrm{H}_{2}-30 \mathrm{~cm} \mathrm{H} \mathrm{O}$, and $-60 \mathrm{~cm} \mathrm{H} \mathrm{H}_{2} \mathrm{O}$. The data were filtered at $2000 \mathrm{~Hz}$ and digitized at $400 \mu \mathrm{sec}$ per point. $B$, Pressure dependence of open probability. The open probability was determined from the fraction of the time the channel was open during a $25 \mathrm{sec}$ current record. 
A

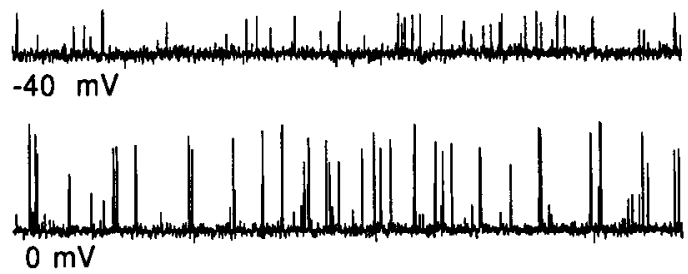

||||||||||||||||||||||

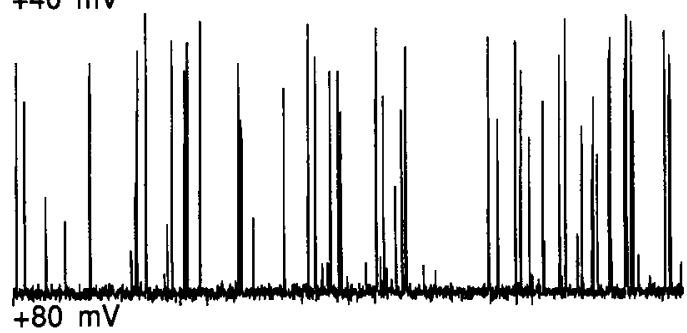

B

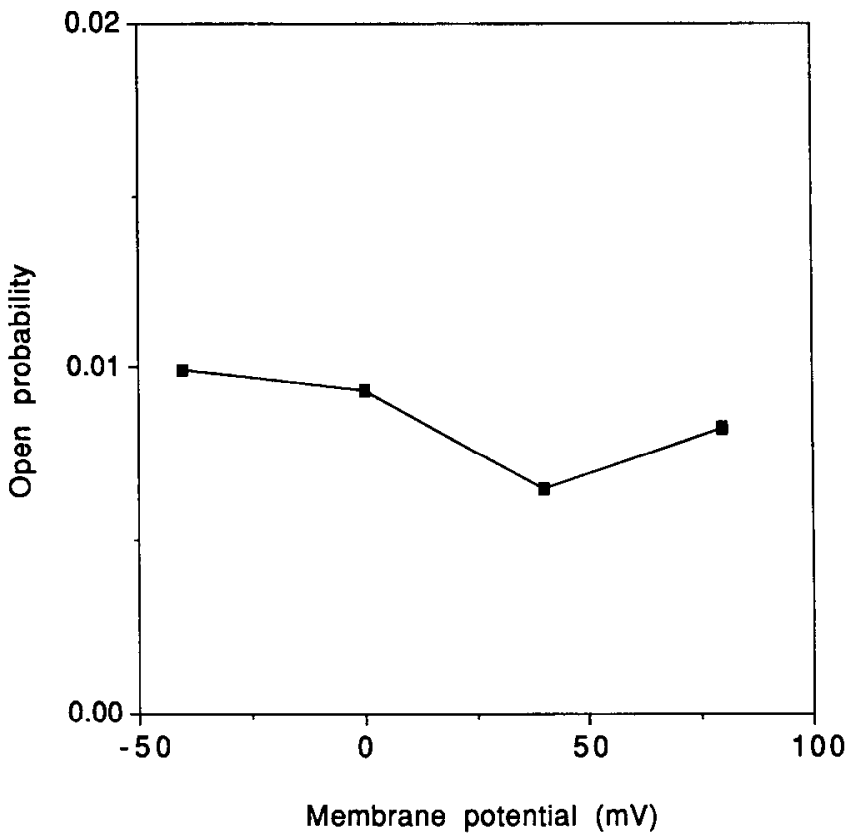

$2 \mathrm{pA}$

$160 \mathrm{~ms}$

Figure 12. Lack of voltage dependence of $\mathrm{K}_{\mathrm{sT}}$ channels. $A$, Representative segments of steady-state records at $-40 \mathrm{mV}, 0 \mathrm{mV}, 40 \mathrm{mV}$, and 80 $\mathrm{mV}$. The data were filtered at $2000 \mathrm{~Hz}$ and digitized at $400 \mu \mathrm{sec}$ per point. $B$, Voltage dependence of open probability. The open probability was determined from the fraction of the time the channel was open during 10-30 sec segments of current records.

pupal muscle (Wei and Salkoff, 1986). While we have not directly attempted to study calcium-activated channels, it is unlikely that any of the channels discussed here are responsible for the calcium-dependent $\mathrm{K}$ current. No calcium was added to the external solution and the internal calcium was buffered to less than $10 \mathrm{~nm}$ with EGTA, making it unlikely for internal calcium concentrations to rise sufficiently to activate calciumdependent currents. In addition, the gating of the $\mathrm{K}_{\mathrm{ST}}$ channel was not affected by $0-100 \mu \mathrm{M}$ calcium concentrations in insideout patches. Channels behaving in a manner similar to all 4 types were observed in cultures from flies with the slowpoke mutation, which abolishes calcium-dependent $\mathrm{K}$ current in pupal and larval muscle (Elkins et al., 1986; Singh et al., 1986). Whole-cell calcium currents were seen when the external solution contained calcium but were not systematically studied.

The outward currents in the cultured embryonic myotubes develop in a sequence similar to the development of currents in the pupal DLMs (Salkoff and Wyman, 1981a). A small delayed outward current appears first, followed by the development of a much larger A-current. In both preparations the A-current is in relative isolation at this stage and can be recorded with minimal contamination by other currents. This stage is followed by a large increase in the delayed outward current. While this sequence of current development is similar in the 2 preparations, the time course over which these events are occurring differs markedly. The outward currents in pupal muscle appear between 55 and $96 \mathrm{hr}$ of pupal development, while the outward currents in the myotubes are mature by $16 \mathrm{hr}$ in culture.

The single $A_{1}$ channels described here differ from other reported single A channels in Drosophila and in other organisms.
$\mathrm{A}_{2}$ channels, which underlie the A-current of cultured larval neurons from Drosophila, are kinetically and genetically distinct from $A_{1}$ channels (Solc et al., 1987). $A_{1}$ channels exhibit a faster, more voltage-dependent macroscopic inactivation rate and inactivate with prepulses about $40 \mathrm{mV}$ more depolarized than $\mathrm{A}_{2}$ channels. The midpoints for inactivation are -95 to $-75 \mathrm{mV}$ for $A_{2}$ channels and -35 to -25 for $A_{1}$ channels. The channels differ in single-channel conductance (13-16 pS for $A_{1}$ vs. 5-8 $\mathrm{pS}$ for $\mathrm{A}_{2}$ ) and in gating behavior. Finally, $\mathrm{A}_{2}$ channels are unaffected by mutations of the $S h$ locus that totally eliminate $A_{1}$ channels. This result suggests that the channels' structures are different, at least in part. The gating of $A_{1}$ channels differs from other A-type channels that have been studied at the singlechannel level. A-type channels from Helix neurons, rat nodose ganglion cells, and guinea pig dorsal root ganglion cells all inactivate more slowly and at more negative voltages (Cooper and Shrier, 1985; Kasai et al., 1986; Taylor, 1987).

The $K_{D}$ channels are responsible for most of the delayed current in cultured myotubes. These channels are similar in conductance and general gating properties to delayed potassium channels in frog skeletal muscle (Standen et al., 1985), mouse macrophages (Ypey and Clapham, 1984), and lymphocytes (DeCoursey et al., 1987; Lewis and Cahalan, 1988), embryonal carcinoma cells (Ebihara and Speers, 1984), and PC12 cells ( $\mathrm{K}_{\mathrm{z}}$ channels: Hoshi and Aldrich, 1988), although some differences in pharmacological sensitivities and gating properties exist among these channels. The $\mathrm{K}_{\mathrm{D}}$ channel in muscle behaves very much like the $\mathrm{K}_{\mathrm{D}}$ channel in cultured larval Drosophila neurons (Solc and Aldrich, 1988). It will be interesting to determine if mutants can be found that affect the nerve and muscle $K_{D}$ channels in 

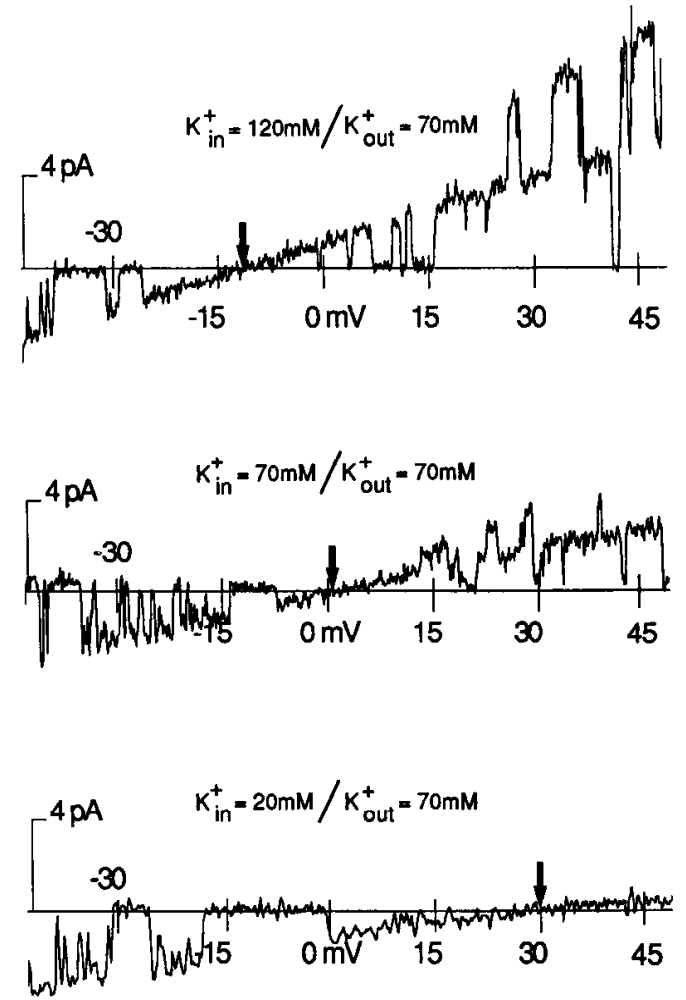

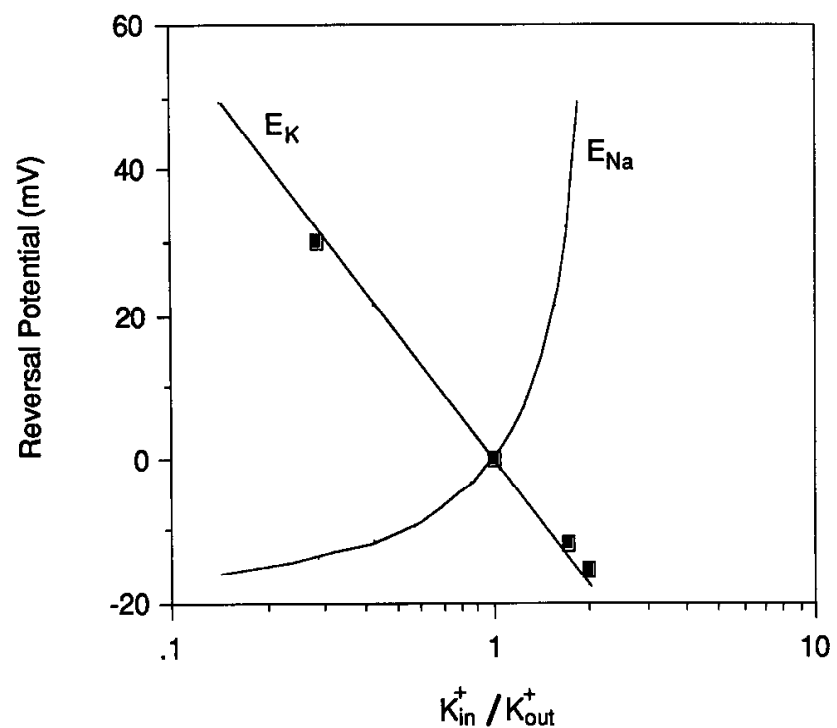

Figure 13. Selectivity of $\mathrm{K}_{\mathrm{ST}}$ channel. $A$, Current records from an inside-out patch containing several $\mathrm{K}_{\mathrm{ST}}$ channels recorded while the voltage was ramped from -50 to $50 \mathrm{mV}$. The current reversal potentials, determined by the zero current intercept of the open channel current on the voltage axis, are indicated by arrows. The external (pipet) solution contained (in mM): $70 \mathrm{NaCl}, 70 \mathrm{KCl}, 4 \mathrm{MgCl}_{2}, 10 \mathrm{HEPES}$, pH 7.1. The internal solutions contained varying $\mathrm{K}^{+}$concentrations as indicated and sufficient $\mathrm{Na}^{+}$so that $\left[\mathrm{K}^{+}\right]+\left[\mathrm{Na}^{+}\right]=140 \mathrm{~mm}$; all other ion concentrations were the same as the external solution. $B$, The reversal potential of the $\mathrm{K}_{\mathrm{sT}}$ channel is plotted as a function of the ratio of the internal to external $\mathrm{K}^{+}$concentrations. The lines on the graph represent the predicted concentration dependence for $\mathrm{K}^{+}$- and $\mathrm{Na}^{+}$-selective electrodes.

the same way or allow them to be distinguished on genetic criteria, similar to the $A_{1}$ and $A_{2}$ channels (Solc et al., 1987).

$\mathrm{K}_{\mathrm{O}}$ channels exhibit voltage-dependent gating but inactivate little during pulses as long as $2.4 \mathrm{sec}$. They probably contribute only a small fraction to whole-cell outward current, however, because most of the noninactivating current $2.4 \mathrm{sec}$ after a voltage step can be accounted for by $\mathrm{K}_{\mathrm{D}}$ channels. This is presumably due to either a low number of $\mathrm{K}_{\circ}$ channels in the myotube membrane or because the channels require additional modulators in order to open with higher probability. It would be difficult to study the properties of the $K_{0}$ channels with macroscopic experiments. The open and closed duration histograms suggest that $\mathrm{K}_{\mathrm{O}}$ channels can be described by a simple kinetic scheme with 1 open and 2 closed states: $C \leftrightarrow C \leftrightarrow O$ with voltage dependence in the $\mathrm{C} \leftrightarrow \mathrm{C}$ and $\mathrm{C} \rightarrow \mathrm{O}$ transitions but not in the closing $(\mathrm{C} \leftarrow \mathrm{O})$ transition.

Many channels have recently been identified which have an increased probability of being open when the cell membrane is stretched. These stretch-sensitive channels vary widely in conductance and selectivity (for review, see Kullberg, 1987). Ámong them, the stretch-activated potassium channels (SAK) from molluscan (Lymnaea stagnalis) ncurons and muscle (Brezden et al., 1986; Sigurdson et al., 1987) bear the closest resemblance to the $K_{\mathrm{sT}}$ channel described here. SAK channels are strongly selective for $\mathrm{K}^{+}$over $\mathrm{Na}^{+}$, do not require internal $\mathrm{Ca}^{2+}$ in order to open, are not very voltage dependent, do not inactivate during maintained applications of pressure, and are sensitive to a similar range of pressures as $\mathrm{K}_{\mathrm{ST}}$ channels. The reported conductance of the SAK channel, $33 \mathrm{pS}$, is lower than that of the $\mathrm{K}_{\mathrm{ST}}$ channel, but this difference may be largely due to the lower ionic strength of solutions used to study SAK channels. Unlike the $\mathrm{K}_{\mathrm{ST}}$ channel, the SAK channel is insensitive to $10 \mathrm{~mm}$ external TEA. Another channel that may be stretch sensitive and selects strongly for $\mathrm{K}^{+}$over $\mathrm{Na}^{+}$has been observed in frog red blood cells (Hamill, 1983). This channel opens in response to hypotonic shock, but its sensitivity to membrane tension has not been directly established. It has a conductance of $18 \mathrm{pS}$ in solutions with a low $\mathrm{K}^{+}$concentration compared with those used in this study and exhibits some calcium sensitivity.

We have no direct evidence bearing on the functional role of the $\mathrm{K}_{\mathrm{ST}}$ channel in fly muscle. It has been suggested that other stretch-activated channels may be involved in osmoregulation. If muscle cells are hypotonically stressed they will swell, possibly opening $\mathrm{K}_{\mathrm{sT}}$ channels; this would lead to an efflux of potassium and the restoration of osmotic balance. Another possibility is that the $\mathrm{K}_{\mathrm{ST}}$ channel regulates membrane excitability during rhythmic muscle contractions such as flight.

Recent evidence regarding alternate splicing of transcripts at the Shaker locus has led to the suggestion that some of the diversity of potassium channel types can be accounted for by diversity in Shaker gene products (Schwarz et al., 1988; Timpe et al., 1988). Our results limit the amount of the diversity that 
A

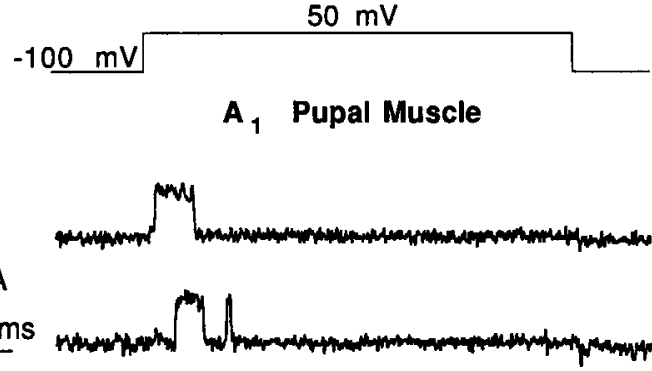

B
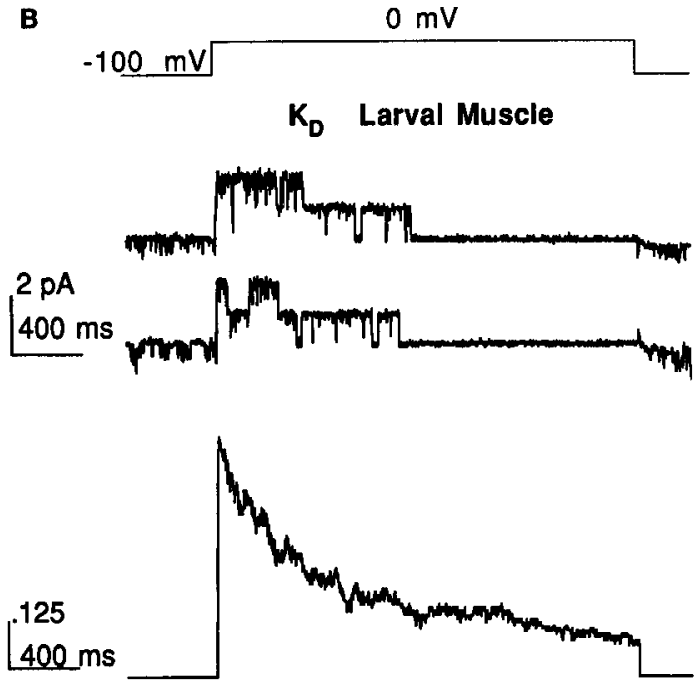

$400 \mathrm{~ms}$

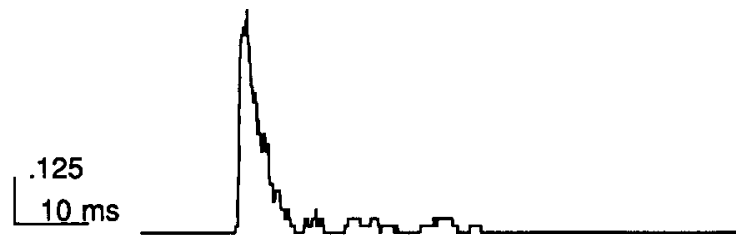

C

$K_{\text {st }}$ Larval Muscle

Control

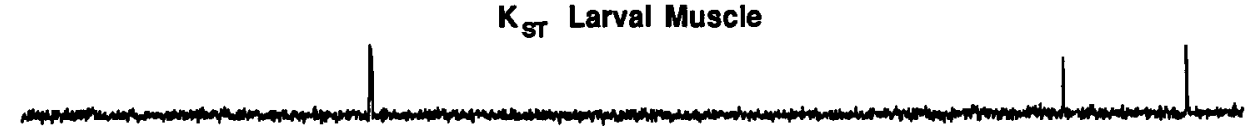

Suction

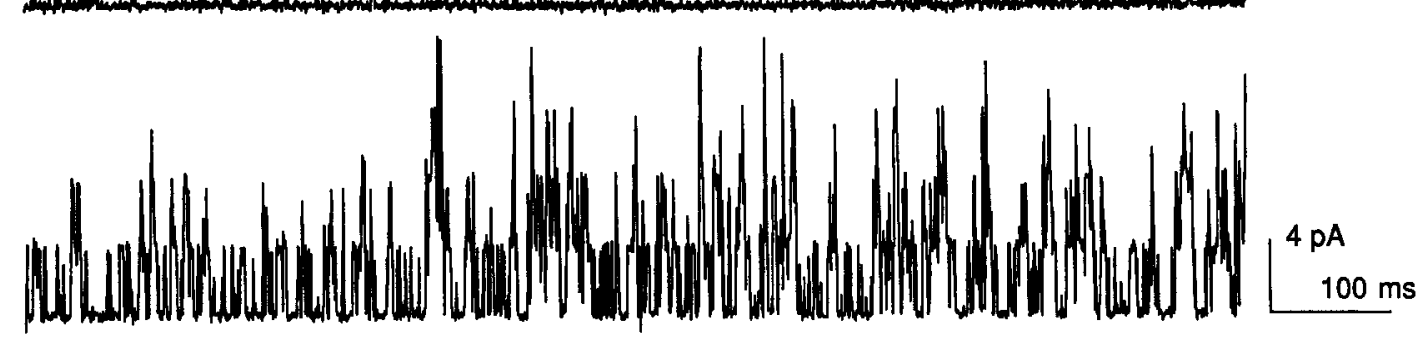

Figure 14. $\mathrm{A}_{1}$ channel in pupal DLMs and $\mathrm{K}_{\mathrm{D}}$ and $\mathrm{K}_{\mathrm{sT}}$ channels in larval body wall muscles. $A$, Single $\mathrm{A}_{1}$ channel currents recorded in a cellattached patch from a pupal DLM with voltage steps to $50 \mathrm{mV}$. The data were filtered at $2000 \mathrm{~Hz}$ and digitized at $50 \mu$ sec per point. $B$, Single $\mathrm{K}_{\mathrm{D}}$ channel currents recorded in a cell-attached patch from a larval body wall muscle fiber with long voltage steps to $0 \mathrm{mV}$. The data were filtered at $400 \mathrm{~Hz}$ and digitized at $1 \mathrm{msec}$ per point. Each panel shows 2 representative current traces followed by an ensemble average of many such traces at the same potential. The ensemble averages are expressed as probabilities. The voltage protocols are shown at the top. $C$, Single $\mathrm{K}_{\mathrm{sT}}$ channel currents recorded in a cell-attached patch on a larval muscle fiber with and without pressure applied to the patch. The magnitude of the pressure was not quantified. Each current trace shows a representative segment of a steady-state current record at $0 \mathrm{mV}$. This patch contained at least $4 \mathrm{~K}_{\mathrm{ST}}$ channels. The data were filtered at $2000 \mathrm{~Hz}$ and digitized at $100 \mu \mathrm{sec}$ per point.

can be explained by such a mechanism. The $K_{D}, K_{S T}$, and $A_{2}$ channels have all been observed in cultures made from flies with the entire Shaker locus deleted from the genome, making it clear that other genes must be involved for these channels. Further work on other excitability mutants and identification of other channel genes by homology to Shaker should prove very useful in understanding the molecular properties of, and relationships between, Drosophila $\mathrm{K}$ channels.

\section{References}

Aldrich, R. W., and C. F. Stevens (1987) Voltage-dependent gating of single sodium channels from mammalian neuroblastoma cells. $\mathrm{J}$. Neurosci. 7: 418-431.

Aldrich, R. W., D. P. Corey, and C. F. Stevens (1983) A reinterpretation of mammalian sodium channel gating based on single-channel recording. Nature 306: 436-441.

Armstrong C. M., and F. Bezanilla (1977) Inactivation of the sodium channel. II. Gating current experiments. J. Gen. Physiol. 70: 567590.

Baumann, A., I. Krah-Jentgens, R. Muller, F. Muller-Holtkamp, R. Seidel, N. Kecskemethy, J. Casal, A. Ferrus, and O. Pongs (1987) Molecular organization of the maternal effect region of the Shaker complex of Drosophila: Characterization of an $\mathrm{I}_{\mathrm{A}}$ channel transcript with homology to vertebrate $\mathrm{Na}^{+}$channel. EMBO J. 6: 3419-3429.
Breitwieser, G. E., and G. Szabo (1985) Uncoupling of cardiac muscarinic and $\beta$-adrenergic receptors from ion channels by a guanine nucleotide analogue. Nature 317: 538-540.

Brezden, B. L., D. R. Gardner, and C. E. Morris (1986) A potassiumselective channel in isolated Lymnaea stagnalis heart muscle cells. J. Exp. Biol. 123: 175-189.

Cooper, E., and A. Shrier (1985) Single-channel analysis of fast transient potassium currents from rat nodose neurones. J. Physiol. (Lond.) 369: 199-208.

Coronado, R., and C. Miller (1979) Voltage-dependent cesium blockade of a cation channel from fragmented sarcoplasmic reticulum. Nature 280: 807-810.

DeCoursey, T. E., K. G. Chandy, S. Gupta, and M. D. Cahalan (1987) Two types of potassium channels in murine T lymphocytes. J. Gen. Physiol. 89: 379-404.

Ebihara, L., and W. C. Speers (1984) Ionic channels in a line of embryonal carcinoma cells induced to undergo neuronal differentiation. Biophys. J. 46: 827-830.

Elkins, T., B. Ganetzky, and C.-F. Wu (1986) A Drosophila mutation that eliminates a calcium-dependent potassium current. Proc. Natl. Acad. Sci. USA 83: 8415-8419.

Ganetzky, B., and C.-F. Wu (1986) Neurogenetics of membrane excitability in Drosophila. Annu. Rev. Genet. 20: 13-44.

Hamill, O. P. (1983) Potassium and chloride channels in red blood cells. In Single-Channel Recording, B. Sakmann and E. Neher, eds., pp. 451-471, Plenum, New York. 
Hamill, O. P., A. Marty, E. Neher, B. Sakmann, and F. J. Sigworth (1981) Improved patch clamp techniques for high-resolution current recording from cells and cell-free membrane patches. Pfluegers Arch. 391: 85-100.

Hoshi, T., and R. W. Aldrich (1988) Voltage-dependent $\mathrm{K}^{+}$currents and underlying single $\mathrm{K}^{+}$channels in pheochromocytoma cells. $\mathrm{J}$. Gen. Physiol. 91: 73-106.

Jan, L. Y., and Y. N. Jan (1976) Properties of the larval neuromuscular junction in Drosophila melanogaster. J. Physiol. (Lond.) 262: 189214.

Kakei, M., A. Noma, and T. Shibasaki (1985) Properties of adenosinetriphosphate-regulated potassium channels in guinea-pig ventricular cells. J. Physiol. (Lond.) 363: 441-462.

Kamb, A., L. E. Iverson, and M. A. Tanouye (1987) Molecular charactcrization of Shaker, a Drosophila gene that encodes a potassium channel. Cell 50: 405-413.

Kasai, H., M. Kameyama, K. Yamaguchi, and J. Fukuda (1986) Single transient $\mathrm{K}$ channels in mammalian sensory neurons. Biophys. J. 49. 1243-1247.

Kullberg, R. (1987) Stretch-activated channels in bacteria and animal cell membranes. Trends Neurosci. 10: 387-388.

Latorre, R., R. Coronado, and C. Vergara (1984) $\mathrm{K}^{+}$channels gated by voltage and ions. Annu. Rev. Physiol. 46: 485-495.

Lewis, R. S., and M. D. Cahalan (1988) Subset-specific expression of potassium channels in developing murine $\mathrm{T}$ lymphocytes. Science 239: 771-775

Logothetis, D. E., Y. Kurachi, J. Galper, E. Neer, and D. E. Clapham (1987) The $\beta \gamma$ subunits of GTP-binding proteins activate the muscarinic $\mathrm{K}^{+}$channel in heart. Nature 325 : 321-326.

Marty, A., and E. Neher (1985) Potassium channels in cultured bovine adrenal chromaffin cells. J. Physiol. (Lond.) 367: 117-141.

Noma, A. (1983) ATP-regulated $\mathrm{K}^{\prime}$ channels in cardiac muscle. Nature 305: 147-148.

Ohnu-Shosaku, T., B. J. Zunkler, and G. Trube (1987) Dual effects of ATP on $\mathrm{K}^{+}$currents of mouse pancreatic $\beta$-cells. Pfluegers Arch. 408: 133-138.

Papazian, D. M., T. L. Schwarz, B. L. Tempel, Y. N. Jan, and L. Y. Jan (1987) Cloning of genomic and complementary DNA from Shaker, a putative potassium channel gene from Drosophila. Science 237: 749-753.

Papazian, D. M., T. L. Schwarz, B. L. Tempel, L. C. Timpe, and L. Y. Jan (1988) Ion channels in Drosophila (in press).

Pfaffinger, P. J., J. M. Martin, D. D. Hunter, N. M. Nathanson, and B. Hille (1985) GTP-binding proteins couple cardiac muscarinic receptors to a $\mathrm{K}^{+}$channel. Nature 317 : 536-538.

Ribalet, B., and S. Ciani (1987) Regulation by cell metabolism and adenine nucleotides of a $\mathrm{K}$ channel in insulin-secreting B cells (RIN m5F). Proc. Natl. Acad. Sci. USA 84: 1721-1725.

Rudy, B (1988) Diversity and ubiquity of K channels. Neuroscience $25 \cdot 729-750$

Salkoff, L. B. (1983a) Drosophila mutants reveal two components of fast outward current. Nature 302: 249-251.

Salkoff, L. B. (1983b) Genetic and voltage-clamp analysis of a Drosophila potassium channel. Cold Spring Harbor Symp. Quant. Biol. 48: 221-231.

Salkoff, L. B., and M. A. Tanouye (1986) Genetics of ion channels. Physiol. Rev. 66: 301-329.

Salkoff, L. B., and R. Wyman (1981a) Outward currents in developing Drosophila flight muscle. Science 212: 461-463.

Salkoff, L. B., and R. Wyman (1981b) Genetic modification of potassium channels in Drosophila Shaker mutants. Nature 293: 228230

Salkoff, L. B., and R. Wyman (1983) lon currents in Drosophila flight muscles. J. Physiol. (Lond.) 337: 687-709.

Schwarz, T. L., B. L. Tempel, D. M. Papazian, Y. N. Jan, and L. Y. Jan (1988) Multiple potassium-channel components are produced by alternative splicing at the Shaker locus of Drosophila. Nature 331 . 137-142.
Seecof, R. L. (1979) Preparation of cell cultures from Drosophila melanogaster embryos. TCA Manual 5: 1019-1022.

Seecof, R. L., and J. J. Donady (1972) Factors affecting Drosophila neuron and myocyte differentiation in vitro. Mech. Age. Dev. 1: 165174.

Seecof, R. L., N. Alleaume, R. L. Templitz, and I. Gerson (1971) Differentiation of neurons and myocytes in cell cultures made from Drosophila gastrulae. Exp. Cell Res. 69: 161-173.

Seecof, R. L., I. Gerson, J. J. Donady, and R. L. Teplitz (1973) Drosophila myogenesis in vitro: The genesis of small myocytes and myotubes. Dev. Biol. 35: 250-261.

Shuster, M. J., and S. A. Siegelbaum (1987) Pharmacological characterization of the serotonin-sensitive potassium channel of Aplysia sensory neurons. J. Gen. Physiol. 90: 587-608.

Sigurdson, W. J., C. E. Morris, B. L. Brezden, and D. R. Gardner (1987) Stretch activation of a $\mathrm{K}^{+}$channel in molluscan heart cells. J. Exp. Biol. 127: 191-209.

Singh, S., C. F. Wu, and B. Ganetzky (1986) Interactions among different $\mathrm{K}^{+}$and $\mathrm{Ca}^{++}$currents in normal and mutant Drosophila larval muscles. Soc. Neurosci. Abstr. 12: 559.

Solc, C. K., and R. W. Aldrich (1988) Voltage-gated potassium channels in larval CNS neurons of Drosophila. J. Neurosci. 8: 2556-2570.

Solc, C. K., W. N. Zagotta, and R. W. Aldrich (1987) Single-channel and genetic analyses reveal two distinct A-type potassium channels in Drosophila. Science 236: 1094-1098.

Spruce, A. E., N. B. Standen, and P. R. Stanfield (1985) Voltagedependent ATP-sensitive potassium channels of skeletal muscle membrane. Nature 316: 736-738.

Standen, N. B., P. R. Stanfield, and T. A. Ward (1985) Properties of single potassium channels in vesicles formed from the sarcolemma of frog skeletal muscle. J. Physiol. (Lond.) 364: 339-358.

Tanouye, M. A., C. A. Kamb, L. E. Iverson, and L. B. Salkoff (1986) Genetics and molecular biology of ionic channels in Drosophila. Annu. Rev. Neurosci. 9: 255-276.

Taylor, P. S. (1987) Selectivity and patch measurements of A-current channels in Helix aspersa neurones. J. Physiol. (Lond.) 388: 437447.

Tempel, B. L., D. M. Papazian, T. L. Schwarz, Y. N, Jan, and L. Y. Jan (1987) Sequence of a probable potassium channel component encoded at Shaker locus of Drosophila. Science 237: 749-753.

Thompson, S. H. (1977) Three pharmacologically distinct potassium channels in molluscan neurones. J. Physiol. (Lond.) 265: 465-488.

Thompson, S. H., and R. W. Aldrich (1980) Membrane potassium channels. In The Cell Surface and Neuronal Function, C. W. Cotman, G. Poste, and G. L. Nicolson, eds., pp. 49-85, Elsevier/North-Holland, Amsterdam.

Timpe, L. C., and L. Y. Jan (1987) Gene dosage and complementation analysis of the Shaker locus in Drosophila. J. Neurosci. 7: 1307-1317.

Timpe, L. C., T. L. Schwarz, B. L. Tempel, D. M. Papazian, Y. N. Jan, and L. Y. Jan (1988) Expression of functional potassium channels from Shaker cDNA in Xenopus oocytes. Nature 331: 143-145.

Wei, A., and L. B. Salkoff (1986) Occult Drosophila calcium channels and twinning of calcium and voltage-activated potassium channels. Science 233: 780-782.

Wu, C.-F., and F. N. Haugland (1985) Voltage clamp analysis of membrane currents in larval muscle fibers of Drosophila: Alteration of potassium currents in Shaker mutants. J. Neurosci. 10: 2626.

Wu, C.-F., B. Ganetzky, F. N. Haugland, and A. X. Liu (1983) Potassium currents in Drosophila: Different components affected by mutations of two genes. Science 220:1076-1078.

Yatani, A., J. Codina, A. M. Brown, and L. Birnbaumer (1987) Direct activation of mammalian atrial muscarinic potassium channels by GTP regulatory protein $G_{\mathrm{k}}$. Science 235 : 207-211.

Yellen, G. (1984) Ionic permeation and blockade in $\mathrm{Ca}^{2+}$-activated $\mathrm{K}^{+}$channels of bovine chromaffin cells. J. Gen Physiol. 84: 157-186.

Ypey, D. L., and D. E. Clapham (1984) Development of a delayed outward-rectifying $\mathrm{K}^{+}$conductance in cultured mouse peritoneal macrophages. Proc. Natl. Acad. Sci. USA 81: 3083-3087. 